TITLE:

\title{
Nucleosomes and epigenetics from a chemical perspective
}

$\operatorname{AUTHOR}(\mathrm{S})$ :

Feng, Yihong; Endo, Masayuki; Sugiyama, Hiroshi

\section{CITATION:}

Feng, Yihong ...[et al]. Nucleosomes and epigenetics from a chemical perspective. ChemBioChem 2021, 22(4): 595-612

\section{ISSUE DATE:}

2021-02-15

URL:

http://hdl.handle.net/2433/261693

\section{RIGHT:}

This is the pre-peer reviewed version of the following article:Y. Feng, M. Endo, H. Sugiyama, ChemBioChem 2021, 22, 595, which has been published in final form at https://doi.org/10.1002/cbic.202000332. This article may be used for noncommercial purposes in accordance with Wiley Terms and Conditions for Use of Self-Archived Versions.; The full-text file will be made open to the public on 23 October 2021 in accordance with publisher's 'Terms and Conditions for SelfArchiving'.; この論文は出版社版でありません。引用の際には出版社版をご確認ご利用ください。; This is not the published version. Please cite only the published version. 


\section{Nucleosomes and epigenetics from a chemical perspective}

\begin{abstract}
Yihong Feng, ${ }^{[a]}$ Masayuki Endo, ${ }^{*[a][b]}$ and Hiroshi Sugiyama*[a] [b]
\end{abstract}
resolution. The recent development of cryo-EM has led to the elucidation of an increasing number of structures. Eleven canonical nucleosome core particle structures in PDB have been solved using cryo-EM. The first crystal structure of a nucleosome core particle was solved in 1997 with a resolution of $2.8 \AA$ (Figure 1), ${ }^{[2]}$ which confirmed Kornberg's nucleosome model based on $X-$ ray fiber diffraction. This nucleosome core particle was reconstituted using human $\alpha$-satellite DNA and shown to recombinantly express histones. In this structure, the histoneoctamer core is wrapped by 1.65-turn left-handed nucleosomal DNA. The histone octamer is formed by four histone heterodimers, i.e., two $\mathrm{H} 2 \mathrm{~A}-\mathrm{H} 2 \mathrm{~B}$ dimers and two $\mathrm{H} 3-\mathrm{H} 4$ dimers. The two $\mathrm{H} 3-$ $\mathrm{H} 4$ dimers form a $\mathrm{H} 3-\mathrm{H} 4$ tetramer that constitutes the center of the octameric structure. The $\mathrm{H} 2 \mathrm{~A}-\mathrm{H} 2 \mathrm{~B}$ dimers interact with the $\mathrm{H} 3-\mathrm{H} 4$ tetramer via a four-helix bundle between the $\mathrm{H} 4$ and $\mathrm{H} 2 \mathrm{~B}$ histone folds, to generate a histone octamer. Because the DNA sequence binds to the histone octamer with the central base pair at the particle pseudo-twofold axis, the DNA is divided into 73and 72-bp halves. The DNA double helix relative to the central base pair is defined as superhelix location zero (SHLO), where the major groove faces the octamer at each successive turn.

In eukaryotic genomes, DNA is packaged into chromatin structures, which encode epigenetic information and maintain genome stability. The nucleosome is the basic unit of the structure of chromatin and was first described by Kornberg using EM in 1974. ${ }^{[1]}$ The canonical nucleosome structure contains a histone octamer core consisting of two pairs of the histone proteins, $\mathrm{H} 2 \mathrm{~A}$, $\mathrm{H} 2 \mathrm{~B}, \mathrm{H} 3$, and $\mathrm{H} 4$, which are wrapped with $145-147$ base pairs (bp) of genomic DNA. Histone variants, histone modifications, and nucleosome-binding proteins are related to nucleosome structure and biological function. Chromatin structures also affect gene expression. Euchromatin is a lightly packed form of chromatin and is normally active during transcription, whereas heterochromatin is more compact and inactive during transcription. In recent years, many breakthrough findings have been reported regarding nucleosomes that have promoted the advancement of epigenetic research. Here, we summarize nucleosome research from a chemical perspective and attempt to provide useful clues for the future research.

\section{Nucleosome structures}

\subsection{Canonical nucleosome structure}

To date, about 34 canonical nucleosome core particle structures have been deposited in the PDB database. Thanks to these structures, we can discuss nucleosome structures at the atomic

[a] Y. Feng, Prof. Dr. M. Endo, Prof. Dr. H. Sugiyama E-mail: Department of Chemistry, Graduate School of Science, Kyoto University

Kitashirakawa-Oiwakecho, Kyoto 606-8502 (Japan)

E-mail: hs@kuchem.kyoto-u.ac.jp

[b] Prof. Dr. M. Endo, Prof. Dr. H. Sugiyama

Institute for Integrated Cell-Material Sciences, Kyoto University

Yoshida-Ushinomiyacho, Kyoto 606-8501 (Japan)

E-mail: endo@kuchem.kyoto-u.ac.jp
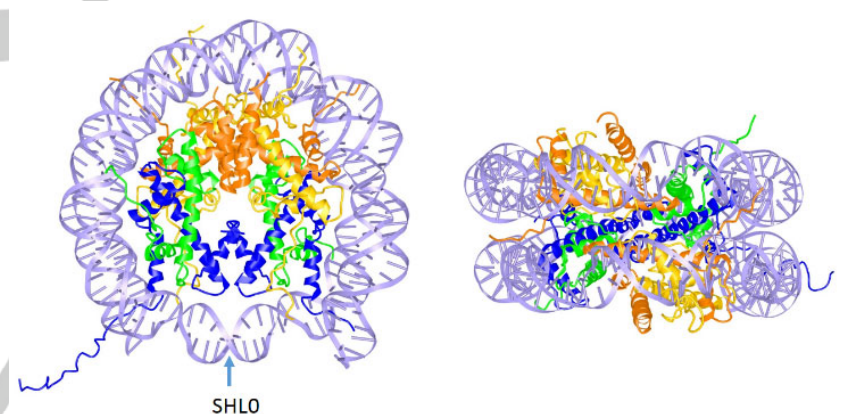

Figure 1. Crystal structure of a nucleosome core particle (PDB: $1 \mathrm{AOI})^{[2]}$ Nucleosome core particle: ribbon traces of the 146-bp DNA phosphodiester backbones and eight histone protein main chains (yellow: $\mathrm{H} 2 \mathrm{~A}$; orange: $\mathrm{H} 2 \mathrm{~B}$; blue: H3; green: H4)

\subsection{Variations in the nucleosome structure}

In addition to the canonical nucleosome structure, different kinds of nucleosome structures have been reported, such as the tetrasome, hexasome, and hemisome. Tetrasome is an intermediate structure formed during the nucleosome folding process. The tetrasome structure, which contains only the $\mathrm{H} 3-$ $\mathrm{H} 4$ tetramer wrapped with DNA, was proposed and reconstituted by several groups using an in vitro reconstitution method. ${ }^{[3],[4]}$ In the tetrasome structure, the DNA wrapped around tetramer exhibits less than one superhelical turn. Recently, the tetrasome structure was also detected in an experiment where RNA polymerase passes through the nucleosome structure which indiates the fragile nature of $\mathrm{H} 2 \mathrm{~A}$ and $\mathrm{H} 2 \mathrm{~B}^{\left[{ }^{[5]}\right.}$ Non-coding RNAs(ncRNAs) take part in chromatin structure modulation ${ }^{[6]}$ and it has been reported that $\mathrm{H} 2 \mathrm{~A}-\mathrm{H} 2 \mathrm{~B}$ eviction activity is exhibited 
by noncoding RNA Eleanor2 which indicates RNAs take part in nucleosome destabilization. ${ }^{[7]}$ In the hexasome, one $\mathrm{H} 2 \mathrm{~A}-\mathrm{H} 2 \mathrm{~B}$ dimer is lost from the nucleosome and the DNA strand that is protected by it has a length of only 110-bp, as measured using MNase treatment. ${ }^{[8]}$ Many researchers have suggested that the hexasome structure exists at the beginning of transcription, ${ }^{[9],[10]}$ which was demonstrated by the elucidation of its cryo-EM structure in 2018. ${ }^{[5]}$

(a)

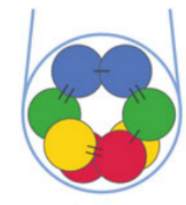

nucleosome nucleosome
core particle

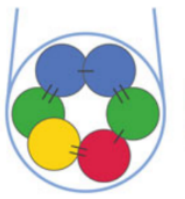

hexasome

H3 $\mathrm{H} 4$

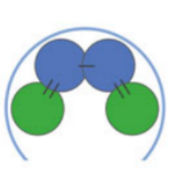

tetrasome

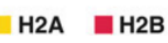

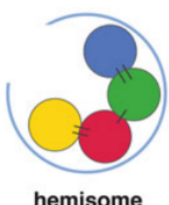

hemisome (b)

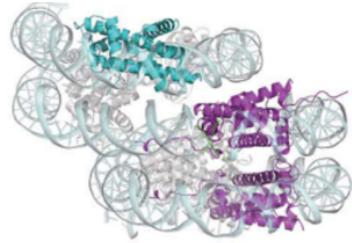

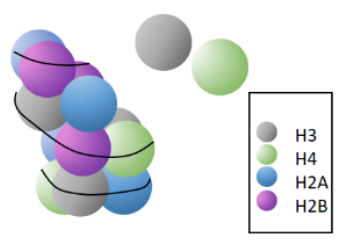

Figure 2 Alternative nucleosome structure. Illustration of nucleosome, hexasome, tetrasome, and hemisome structures. ${ }^{[11]}$ (a) Structure of the overlapping dinucleosome (left) and its illustration (right). (b) The H2A-H2B dimers are presented in magenta and light blue in the schematic image (right). ${ }^{[12]}$

In addition, a special complex containing only one pair of the $\mathrm{H} 2 \mathrm{~A}, \mathrm{H} 2 \mathrm{~B}, \mathrm{H} 3$, and $\mathrm{H} 4$ histone proteins with a DNA strand has been proposed and is called the hemisome. This kind of structure was found in the CENP-A nucleosome, which is a type of nucleosome that is assembled from the centromere-specific histone $\mathrm{H} 3$ variant CENP-A. Using atomic force microscopy and biochemical methods, researchers found that the CENP-A nucleosome has a heterotypic tetrasome (hemisome) structure. ${ }^{[13],[14]}$ The existence of hemisomes is still argued. In $S$. Cerevisiae, in vivo chemical cleavage data shows the existence of hemisomes, ${ }^{[15]}$ even though in humans most of CENP-A nucleosomes consist of octamers. ${ }^{[16]}$

The overlapped dinucleosome was first described by the group of Tom Owen-Hughes in 2009. ${ }^{[17]}$ Their work indicated that this kind of special nucleosome may exist when remodeling factors reposition the nucleosome. The crystal structure of the overlapped dinucleosome was reported in 2017 (Figure 2b). ${ }^{[12]}$ In this report, using a 250-bp DNA and histones $\mathrm{H} 2 \mathrm{~A}, \mathrm{H} 2 \mathrm{~B}, \mathrm{H} 3$, and $\mathrm{H} 4$, an overlapped dinucleosome and a canonical mononucleosome were reconstituted. The overlapped dinucleosome consists of an octameric structure that has contacts with a hexamer (i.e., an octamer that has lost one $\mathrm{H} 2 \mathrm{~A}-\mathrm{H} 2 \mathrm{~B}$ dimer). The DNA wrapped around this kind of dinucleosome is in a three-turn, left-handed form. A genome-wide analysis of this kind of dinucleosome was performed in Hela cells which suggested that the overlapping dinucleosome is predominantly formed at the regions just downstream of transcription start sites

which is consistent with chromatin remodeling factor remodelling the chromatin structure at the TSS to form the nucleosome free region. This structure may shed light on how nucleosome repositioning occurs during the chromatin remodeling process.

An abnormal in vitro octasome structure was reported in $2018 .{ }^{[18]}$ Using only a tetramer and DNA, this kind of $\mathrm{H} 3-\mathrm{H} 4$ octasome structure was reconstituted in vitro and characterized using high-speed atomic force microscopy (HS-AFM). It has a core protein size similar to that of the common nucleosome; however, the histone-binding DNA region is shorter than that of the nucleosome. Regarding its biochemical properties, the $\mathrm{H} 3-\mathrm{H} 4$ octasome displayed a one-step histone-dissociation pattern under heat treatment and distinct micrococcal nuclease and peplomycin accessibility. These findings indicate that this kind of new octasome has a wrapping pattern different from a nucleosome. $\mathrm{H} 3-\mathrm{H} 4$ octasome could be a folding intermediate during nucleosome formation.

(a) Histone $\mathrm{H3}$

H3

H3.3

CENP-A

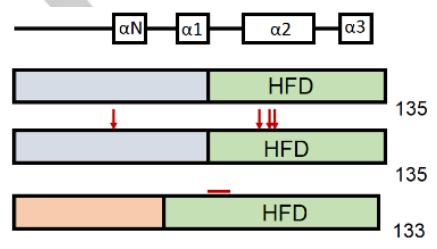

Histone H2A
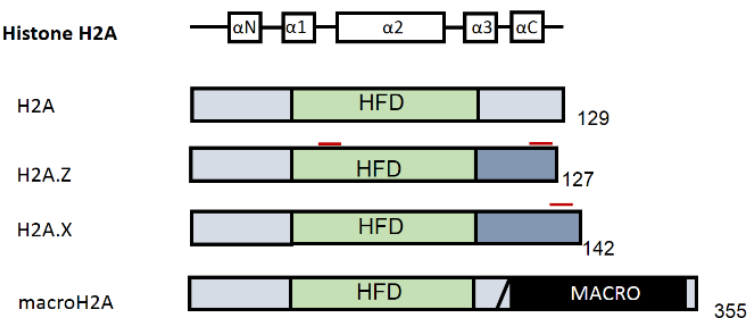

(b)
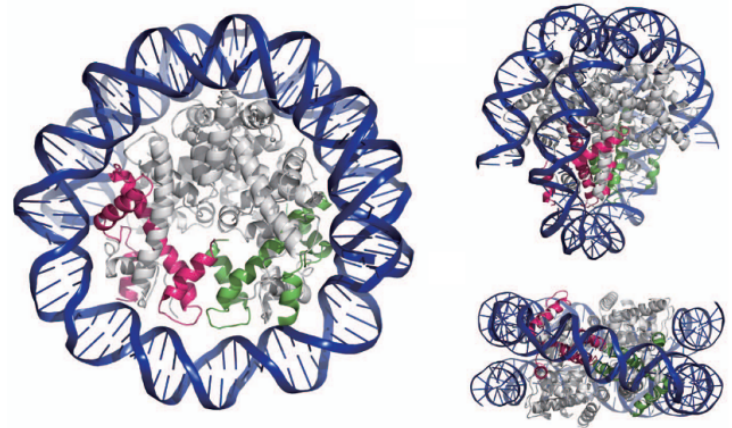

Figure 3. Different types of histone variants. (a) Protein domain structure of histone variants. HFD, histone folding domain (where histone dimerization occurs). The regions of sequence variation in histone variants are indicated in red (the structures at the top are illustrations of the structures of the $\mathrm{H} 3$ and $\mathrm{H} 2 \mathrm{~A}$ proteins $\left.^{[19]}\right)$. (b) Three different views of the CENP-A nucleosome structure. ${ }^{[20]}$ Two CENP-A molecules are shown in magenta and green.

\subsection{Histone variants and functions}

Unlike canonical histones, which play various roles in gene expression, distinct histones occur in different chromosomal 
processes, such as DNA repair, meiotic recombination, chromosome segregation, transcription initiation and termination, and sex chromosome condensation. Interestingly, histone variants exist for $\mathrm{H} 2 \mathrm{~A}$ and $\mathrm{H} 3$, but not for $\mathrm{H} 2 \mathrm{~B}$ and $\mathrm{H} 4$. The protein domain structures of some these histone variants are presented in Figure 3a. The main functions of the common histone variants are listed in Table 1. Research on histone variants has been accelerated by the combination of next-generation sequencing techniques and chromatin immunoprecipitation (ChIP), which is termed ChIP-seq.

Table 1. Main functions of histone variants.

\begin{tabular}{lll}
\hline $\begin{array}{l}\text { Histone } \\
\text { variant }\end{array}$ & Function & Reference \\
\hline CENP-A & Kinetochore assembly & {$[21][22]$} \\
H3.3 & Transcriptional activation & {$[23][24][25][26]$} \\
H2A.Z & $\begin{array}{l}\text { Gene expression, chromosome } \\
\text { segregation }\end{array}$ & {$[$ [27][28][29][30][31][32][33] } \\
H2A.X & DNA repair and recombination & \\
macroH2A & $\begin{array}{l}\text { X chromosome inactivation, gene } \\
\text { repression, } \\
\text { help enforce existing expression patterns in } \\
\text { fluctuating conditions }\end{array}$ \\
\hline
\end{tabular}

CENP-A is an $\mathrm{H} 3$ histone variant that is specifically located at the centromere. CENP-A exhibits about $50-60 \%$ conservation of the histone folding domain (HFD) of $\mathrm{H} 3$, even though there is no conservation in its N-terminal tail. CENP-A can be found in all types of eukaryote genomes. ${ }^{[37]}$ The crystal structure of the CENP-A nucleosome was reported in 2011, which is shown in Figure $3 b^{[20]}$ In contrast to the canonical nucleosome, in which a 147-bp DNA strand wraps around the octamer, DNA of only 121$\mathrm{bp}$ is wrapped around the CENP-A nucleosome. The special loop1 structure, which is marked as a short red horizontal line in Figure $3 a$, exists only in CENP-A and contributes to the stable CENP-A retention at centromeres. Loop 1 of the CENP-A nucleosome plays an important role in stabilizing centromeric chromatin, and loop 1 mutation reduces the centromeric localization of CENP-A. How is the CENP-A nucleosome targeted to the centromere? HJURP is CENP-A specific chaperone and it is required during the recruitment of new CENP-A to nucleosomes at replicated centromeres. ${ }^{[38][39]}$ Other factors such as CENP-C are also important for CENP-A localization. CENP-C is important for recruiting CENP-A to centromeres. ${ }^{[21]}$

$\mathrm{H} 3.3$ levels are elevated in gene bodies, at promoters, at enhancers, and at transcription termination sites. ${ }^{[23],[24]}$ The H3.3 histone is very similar to $\mathrm{H} 3$, differing only at four amino acids. H3.3 was originally found to be enriched at actively transcribed genes and is incorporated via a DNA-synthesis-independent process. ${ }^{[25],[40]}$ This histone variant marks transcriptionally active regions of the chromatin and plays a role in gene activation.

$\mathrm{H} 2 \mathrm{~A} . \mathrm{Z}$ is reportedly localized in the transcription start site (TSS) region and enhancers. ${ }^{[30],[31],[28]}$ H2A.Z shares $\sim 60 \%$ similarity with canonical $\mathrm{H} 2 \mathrm{~A}$ and is conserved among species. Two different isoforms of H2A.Z have been identified, H2A.Z.1 and H2A.Z.2. These two isoforms differ by only three amino acids. The structure of the H2A.Z nucleosome was solved in 2010, which revealed an extended acidic patch, a pattern that is related to its function. ${ }^{[33]}$ H2A.Z can be modified by $\bar{a}$ variety of posttranslational modifications, including acetylation, ubiquitylation, and sumoylation. The biological function of the H2A.Z nucleosome has been studied in detail. It plays roles in transcription regulation, DNA repair, heterochromatin formation, and chromosome segregation. ${ }^{[27],[28],[29]}$

The H2A.X variant is defined by the presence of a carboxyterminal amino acid sequence motif, $S \bar{Q}(\mathrm{E}$ or $\mathrm{D}) \varnothing(\varnothing$ indicates a hydrophobic amino acid). The H2A.X histone is involved in DNA double-strand break repair. ${ }^{[34]}$ After DNA damage, the serine residues become phosphorylated $(\gamma \mathrm{H} 2 \mathrm{~A} . \mathrm{X})$, followed by the spread of H2A.X phosphorylation along the chromosome. After the repair of double-strand breaks by homologous recombination or nonhomologous end-joining, this phosphorylation mark is removed. Laser microirradiation is commonly used to introduce DNA damage in a defined submicrometer region in the nucleus and is applied to the study of protein recruitment to the DNA lesion or modification at the DNA lesion. ${ }^{[41]}$ Phosphorylated H2A.X can be recruited using this method and acts as a hallmark indicator of the presence of DNA breaks.

\section{Nucleosome positioning sequence}

In in vitro nucleosome studies, the nucleosome positioning sequence is widely used to prepare homogeneously positioned nucleosomes. A DNA sequence containing TT, AA, and TA separated by 10-bp can bend easily and exhibits a high binding affinity for the histone octamer. These include $\sim 10$-bp periodic AA/TT/TA dinucleotides that oscillate in phase with each other and out of phase with 10-bp periodic GC dinucleotides because the minor grooves of AT-rich sequences are narrower than those of GC-rich sequences which enables AT-rich sequence to better suffer the minor groove compression. ${ }^{[42]}$.

Two types of nucleosome positioning sequences are widely used for in vitro nucleosome reconstitution. The first type is an $\alpha$ satellite in the natural gene sequence. ${ }^{[43],[44]}$ The other type is the 601 nucleosome positioning sequence, which was developed in $1998 .{ }^{[45]}$ The 601 sequence was selected from random synthetic DNA molecules for having the highest affinity for histone-octamer binding using the SELEX method. The X-ray crystal structure of the nucleosome core particle composed of the Widom 601 DNA sequence has been solved (PDB number, 3LZ0). Using the 601 sequence, precisely positioned nucleosomes can be produced and thus it is widely used in in vitro nucleosome study and provides the foundation for understanding nucleosome biochemistry, such as chromatin structure, interaction between nucleosome and its binding factors and nucleosome remodelling. In addition, the NuPOP software was developed to predict nucleosome occupancy on DNA sequences. ${ }^{[46]}$ It is a fast software tool for predicting nucleosome positioning which can help us to understand how a genome's nucleosome organization facilitates genome function. 


\section{Nucleosome assembly and remodeling}

\subsection{Chaperone-assisted nucleosome assembly}

In in vitro studies, a popular method to assemble chromatin for in vitro applications is via salt gradient deposition (SGD), which involves decreasing ionic strength. In this procedure, nucleosome assembly is a two-step process. First, two $\mathrm{H} 3-\mathrm{H} 4$ dimers or one $\mathrm{H} 3-\mathrm{H} 4$ tetramer is deposited on DNA to form a tetrasome, followed by the binding of two $\mathrm{H} 2 \mathrm{~A}-\mathrm{H} 2 \mathrm{~B}$ dimers to the tetrasome and the wrapping of the remaining DNA around the octamer, to complete the nucleosome structure (a simple illustration of this process is presented in Figure 4).${ }^{[4]}$ In contrast, in the process of nucleosome disassembly by raising the ionic strength (salt dissociation), the $\mathrm{H} 2 \mathrm{~A}-\mathrm{H} 2 \mathrm{~B}$ dimer is lost and one turn of DNA unwraps from the structure, followed by tetrasome loss from the DNA. In cells, all of these steps are coordinated by histone chaperones. In the following section, we describe the functions of histone chaperones in the nucleosome assembly process.

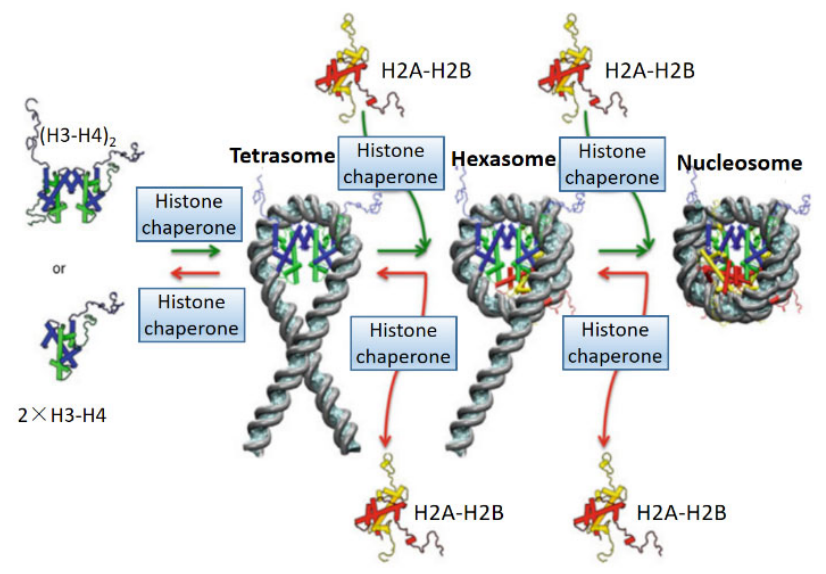

Figure 4. Schematic representation of the stepwise assembly and disassembly of the nucleosome core particle. ${ }^{[48]}$ Green arrowheads represent the nucleosome assembly process while red arrowheads represent the nucleosome disassembly process.

\subsubsection{Histone $\mathrm{H} 3-\mathrm{H} 4$ deposition}

Many chaperones, such as CAF-1 and ASF-1, play roles in $\mathrm{H} 3-$ $\mathrm{H} 4$ histone deposition. ${ }^{[49],[50]}$ Here, we describe the function of CAF-1 in detail. CAF-1 is a key factor for the nucleosome assembly associated with DNA replication. The CAF-1 complex contains three subunits, named Cac1, Cac2, and Cac3 in yeast (p150, p60, and $\mathrm{p} 40$ in humans). The detailed working mechanism of CAF-1 was proposed in 2017 (Figure 5). ${ }^{[51]}$ After $\mathrm{H} 3-\mathrm{H} 4$ binding, CAF-1 is activated and the WHD domain is released from the acidic region of Cac1. DNA binding promotes the formation from two ACF-1-( $\mathrm{H} 3-\mathrm{H} 4)$ complexes of an $\mathrm{H} 3-\mathrm{H} 4$ tetramer. Subsequently, $(\mathrm{H} 3-\mathrm{H} 4)_{2}$ histones are directly sequestered from CAF-1. Finally, $(\mathrm{H} 3-\mathrm{H} 4)_{2}$ are transferred to DNA to form the tetrasome and the WHD domain of CAF-1 rebinds to the acidic region of Cac1.

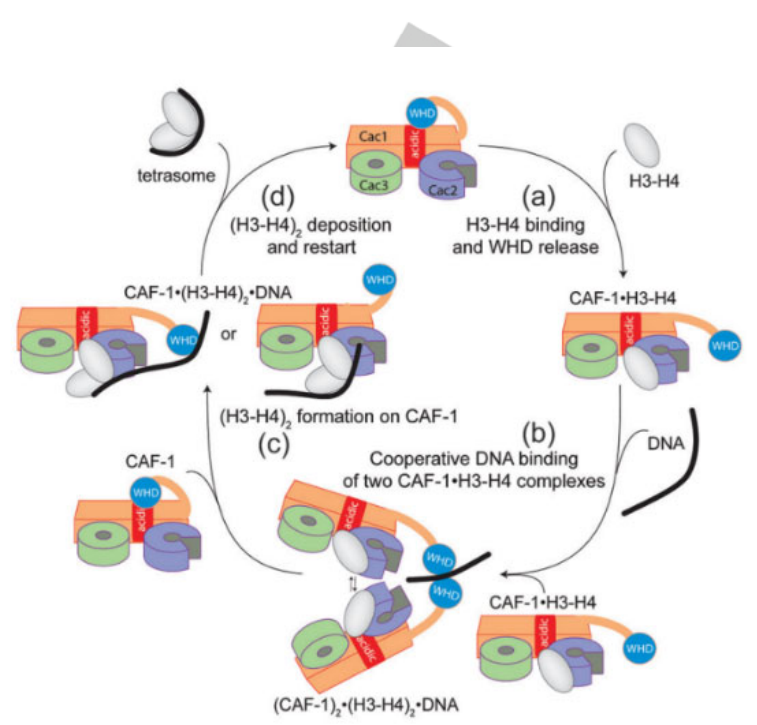

Figure 5. Working model of CAF-1 medicated tetrasome assembly. ${ }^{[51]}$

(a)

HISTONE H3 DEPOSITION

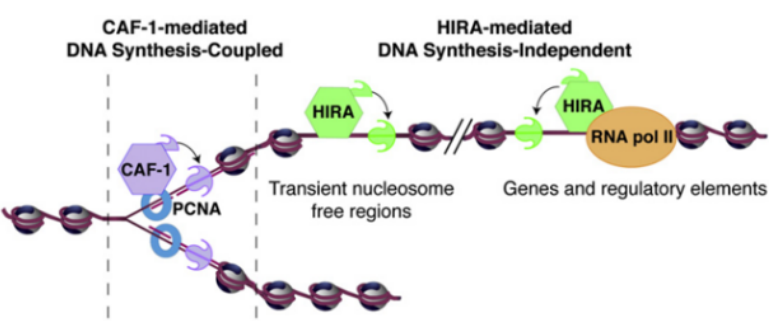

(b)

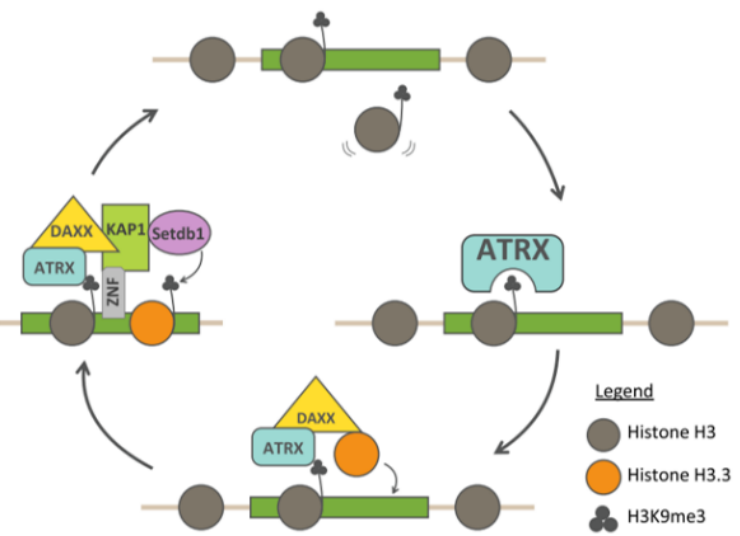

Figure 6. H3.3 deposition mediated by HIRA and ATRX. (a) The HIRA complex mediates $\mathrm{H} 3.3$ deposition broadly by binding to transient accessible nonnucleosomal DNA. ${ }^{[52]}$ (b) ATRX recognizes H3K9me3 and acts with DAXX to deposit H3.3. ${ }^{[53]}$

In contrast to canonical histone deposition, the HIRA complex and the ATRX/DAXX complex are representative chaperones for 
the deposition of the $\mathrm{H} 3.3$ variant. $\mathrm{H} 3.3$ deposition on euchromatin is dependent on HIRA, ${ }^{[54]}$ whereas H3.3 deposition on heterochromatin is carried out by ATRX/DAXX.[55] During postreplication, sperm programming, and any event that generates transient naked DNA, the HIRA complex mediates H3.3 deposition, broadly by binding to transient accessible nonnucleosomal DNA (Figure 6a). The HIRA complex deposits $\mathrm{H} 3.3$ onto the gene coding region, while the ATRX/DAXX complex is responsible for $\mathrm{H} 3.3$ deposition at repetitive regions of the genome. ${ }^{[56]}$ A recent report has also indicated that the ATRX/DAXX chaperone complex deposits $\mathrm{H} 3.3$ to maintain H3K9me3 modification in heterochromatin throughout the genome (Figure 6b). ${ }^{[53]}$ The ability of ATRX to recognize and resolve G-quadruplex structures has also been reported. ${ }^{[57],[58]}$

\subsubsection{H2A-H2B deposition}

$\mathrm{H} 2 \mathrm{~A}-\mathrm{H} 2 \mathrm{~B}$ deposition too requires the assistance of histone chaperones, such as Nap1, ${ }^{[59]}$ FACT, ${ }^{[60]}$ and Hif1. ${ }^{[61]}$ In 2016, the crystal structure of the classic chaperone, NAP1 for H2A-H2B deposition was reported, as shown in the Nap1-mediated H2A$\mathrm{H} 2 \mathrm{~B}$ chaperoning and nucleosome assembly model depicted in Figure $7 .{ }^{\left[{ }^{[2]}\right]} \mathrm{Nap}-1$ binds to $\mathrm{H} 2 \mathrm{~A}-\mathrm{H} 2 \mathrm{~B}$, which is synthesized in the cytoplasm. The Nap-1-H2A-H2B complex oligomerizes and the NLS becomes accessible to karyopherin Kap114p, resulting in nuclear transport. In the nucleus, Nap-1 deposits H2A-H2B onto the hexasome.

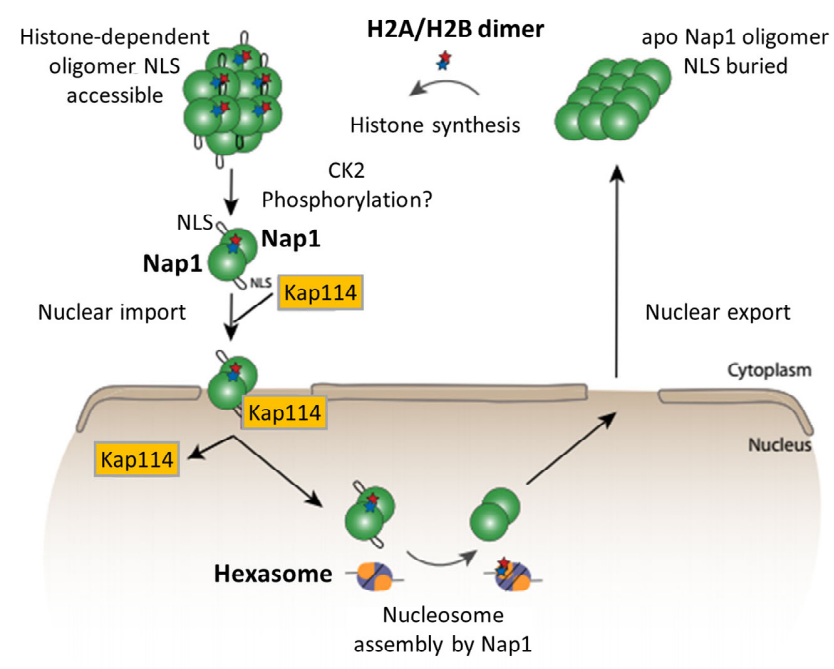

NLS: nuclear localization sequence

Figure 7. Model of Nap1 as a $\mathrm{H} 2 \mathrm{~A}-\mathrm{H} 2 \mathrm{~B}$ transporter and chromatin-assembly factor. $^{[62]}$

\subsection{Nucleosome remodelling}

Nucleosome remodellers play critical roles in chromatin dynamics. ATP-dependent remodelling complexes play roles in histone sliding and ejection or in the incorporation of histone variants, which contribute to dynamics in gene regulation and chromatin function. Chromatin remodellers can be divided into four subfamilies, i.e., imitation switch (ISW1), chromodomain helicase DNA-binding (CHD), switch/sucrose nonfermentable (SWI/SNF),

and INO80. ${ }^{[63],[64]}$ The main functions of remodelers are explained as follows (also see Figure 8).

Two types of functions of the ISW1 and CHD remodellers in nucleosome assembly have been defined: (1) promotion of the maturation of the initial histone-DNA complexes (prenucleosomes) into canonical octameric nucleosomes ${ }^{[65],[66]}$ and (2) spacing of nucleosomes at relatively fixed distances. ${ }^{[67],[68],[69]}$

The chromatin assessment function is mainly carried out by the SWI/SNF complex, including sliding and ejecting nucleosomes and evicting nucleosome components. This complex increases chromatin accessibility to provide binding sites to transcription factors. ${ }^{[70]}$

The INO80 remodeller can edit nucleosomes, i.e., it can remove a histone from a nucleosome structure and replace it with histone variants or canonical histones. This process is aided by editing remodellers, such as the yeast Swr1 complex (SWR1C) and the mammalian Snf2-related CBP activator protein (SRCAP), to help deposit H2A.Z into the nucleosome. ${ }^{[71],[72]}$

The structures of the complexes of remodellers and nucleosomes provide insight into the remodelling mechanism. The development of cryo-EM techniques led to the recent resolution of the SWI/SNF-nucleosome complex, RSCnucleosome complex and INO80-nucleosome complex and CHDnucleosome complex. ${ }^{[73],[74][75][76]}$

Nucleosome assembly DNA

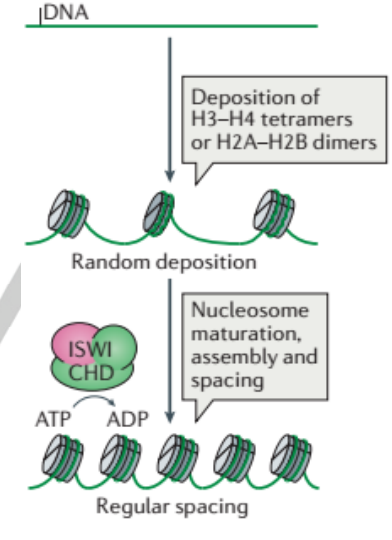

Nucleosome editing

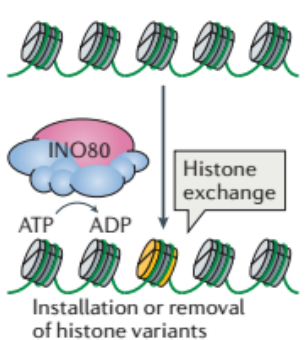

Figure 8. Functional classification of nucleosome remodellers. ${ }^{[77]}$ Nucleosome assembly: specific ISWI and CHD subfamily remodellers. Chromatin access: primarily SWI/SNF subfamily remodellers. Nucleosome editing: INO80 subfamily (INO80C or Swr1 complex (SWR1C)) 


\section{Epigenetic modifications}

Epigenetic modifications, such as DNA methylation and histone modifications, affect gene expression in mammalian cells. The study and understanding of epigenetic codes will promote knowledge of the molecular mechanisms of epigenetic gene regulation. (a)

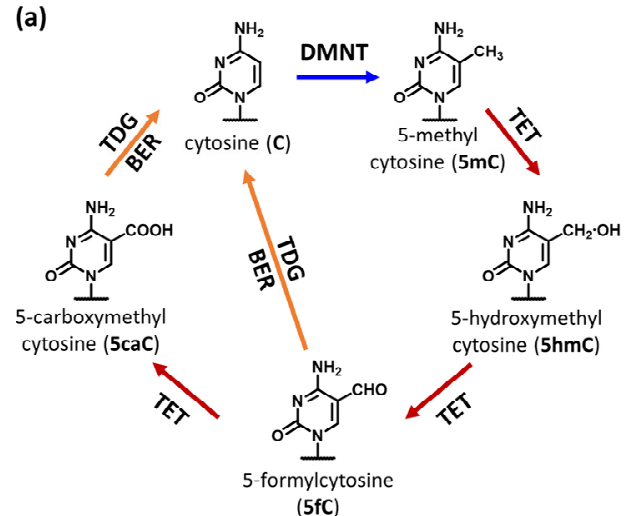

(b)
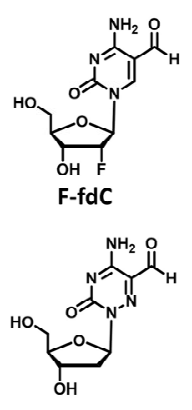

a-fdC
Figure 9. Cytosine methylation. (a) Processes of cytosine methylation and demethylation. DMNTs (DNA methyltransferases) catalyze cytosine methylation while ten-eleven translocation methylcytosine dioxygenase (TET), base excision repair (BER), and thymine-DNA glycosylase (TDG) catalyze the cytosine demethylation process. (b) Chemical structures of F-fdC and a-fdC.

\subsection{DNA methylation and demethylation}

DNA methylation is a well-studied epigenetic modification. DNA methylation in the promoter region is usually related to the suppression of downstream genes, ${ }^{[78]}$ while DNA methylation in the gene body is related to active transcription. ${ }^{[79]}$ The DNA methylation process has been widely studied, especially cytosine methylation and demethylation, which are directly related to epigenetic gene expression. The degree of cytosine methylation and demethylation is regulated and balanced in a dynamic fashion.
The chemical processes of cytosine methylation and demethylation are presented in Figure 9. In the human genome, DNA methyltransferases (DNMTs) catalyze cytosine methylation by transferring the methyl group of S-adenosylmethionine (SAM) to cytosine at $\mathrm{CpG}$ dinucleotides. ${ }^{[80]}$ In the process of demethylation, ten-eleven translocation methylcytosine dioxygenase (TET) catalyzes the major pathway of DNA demethylation: it converts 5-methylcytosine $(5-\mathrm{mC})$ to 5hydroxymethylcytosine $(5-\mathrm{hmC})$ and further to 5-formylcytosine (5-fC) and 5-carboxylcytosine (5-caC). ${ }^{[81],[82],[83]}$ Recently, based on a DNA origami nanochip, the behaviors of the TET enzyme in the demethylation process were observed and analyzed. ${ }^{[84]}$ The 5-fC and 5-caC molecules are recognized and excised by thymine-DNA glycosylase (TDG) and replaced with unmethylated cytosine via a base excision repair (BER) pathway. ${ }^{[82]} A$ second pathway that converts 5 -fC to cytosine upon $\mathrm{C}-\mathrm{C}$ bond cleavage was also proposed. This kind of reaction requires the activation of the nucleobase by nucleophilic addition to the C6 position. Recently, a 6-aza-5-formyl-deoxycytidine (a-fdC) probe molecule was developed. ${ }^{[85]}$ After feeding a-fdC and a 2'-fluorinated fdC analogue $(\mathrm{F}-\mathrm{fdC})$ to somatic cell lines and induced mouse embryonic stem cells, only deformylation of F-fdC was clearly observed, which suggested that the $\mathrm{C}-\mathrm{C}$ bond-cleaving deformylation is initiated by nucleophilic activation.

\subsection{Histone modification}

Histone posttranslational modifications (PTMs), including acetylation, methylation, ubiquitination, and phosphorylation (Figure 10a), are widely distributed across the whole genome. The human core histone modifications are shown in Figure 10b. PTMs are regulated by specific histone-modifying enzymes called "writer," "reader," and "eraser," such as histone acetyltransferases (HATs) and histone deacetylases (HDACs), histone methyltransferases (HMTs), and histone demethylases (HDMs).

The chemical synthesis of the histone code is useful for in vitro studies. Because this has been explained in detail in many reviews, ${ }^{[86],[87]}$ we will not describe those studies here. (a) Histone acetylation

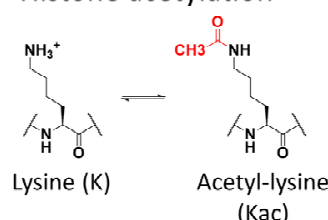

Histone methylation (lysine)

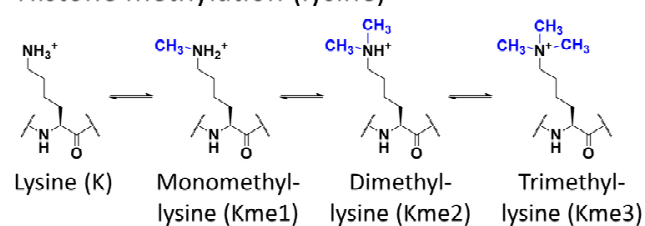

\section{Histone ubiquitination (lysine)}

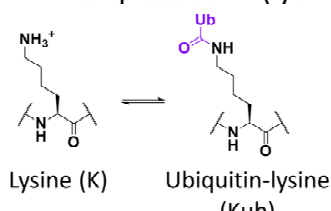

(b) Histone modification

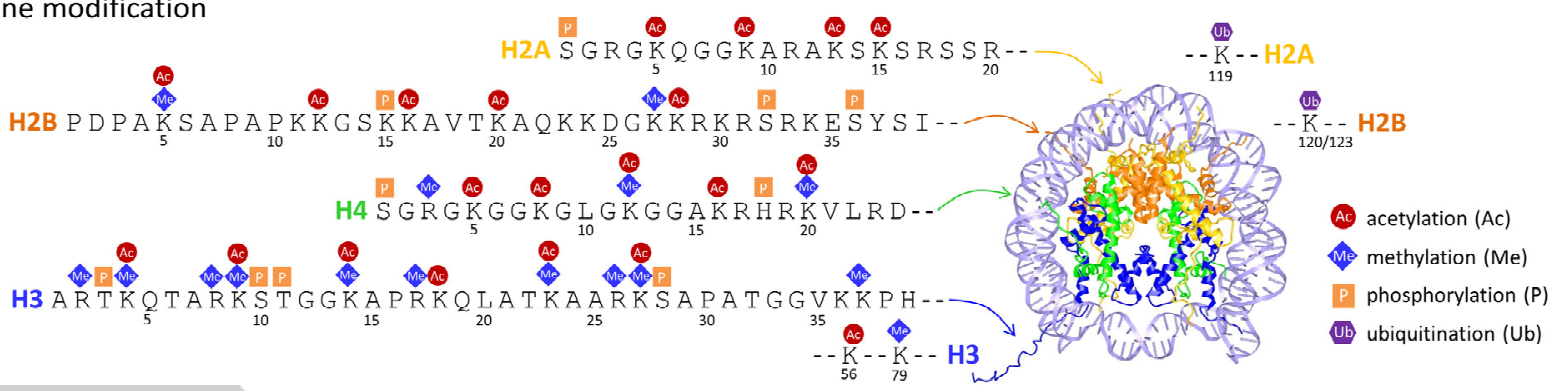

Figure 10. Histone modification. Histone (a) PTMs: Iysine acetylation, lysine methylation (mono/di/tri), and lysine ubiquitination. (b) Mammalian core histone modifications of $\mathrm{H} 2 \mathrm{~A}, \mathrm{H} 2 \mathrm{~B}, \mathrm{H} 3$, and $\mathrm{H} 4$. ${ }^{[149]}$ 


\subsubsection{Histone acetylation}

Histone acetylation was the first histone modification described in the literature (in 1961). ${ }^{[88]}$ The histone acetylation states are highly dynamic, with half-lives in the range of minutes in transcriptionally active chromatin. ${ }^{[89]}$ Acetylation reduces the positive charge of lysine residues which decreases the interaction between nucleosomal DNA and histones and histone protein-protein interaction, thus increasing the accessibility of DNA to promote transcription. ${ }^{[90]}$ This charge-neutralization model was proved using microarray assays in yeast strains. ${ }^{[91],[92]}$

\subsubsection{Histone methylation}

Because histone methylation does not affect the charge of the histone tail, the effect of this modification on gene regulation is indirect. Lysine methylation is related not only to gene repression but also to gene activation. H3K9me3 and H3K27me3 modification play critical roles in gene repression and heterochromatin formation. In the case of this type of modification, these molecules can recruit specific proteins to the modified lysine residue. For instance, HP1 specifically bounds to H3K9 trimethylation and $\mathrm{H} 3 \mathrm{~K} 27$ trimethylation is recognized by polycomb proteins, further triggering the repression of transcription.

In contrast to $\mathrm{H} 3 \mathrm{~K} 9 \mathrm{me} 3$ and $\mathrm{H} 3 \mathrm{~K} 27 \mathrm{me} 3, \mathrm{H} 3 \mathrm{~K} 4$ methylation is related to transcriptional activation. H3K4 methylation is deposited by mixed-lineage leukemia (MLL) family methyltransferases which is stimulated by the monoubiquitination of histone $\mathrm{H} 2 \mathrm{~B}$ on lysine 120 (H2BK120ub1). ${ }^{[93],[94],[95]}$ Recently, the cryo-EM structures of the human MLL1 and MLL3 catalytic modules associated with nucleosome core particles containing H2BK120ub1 or unmodified H2BK120 were reported. ${ }^{[96]}$

\subsubsection{Histone ubiquitination}

During the process of ubiquitination, the 76 -amino-acid protein ubiquitin is conjugated to histone lysine residues via the sequential action of three enzymes: E1-activating, E2-conjugating and E3-ligating enzymes. Histone ubiquitination can affect nucleosome dynamics and regulate gene expression. Monoubiquitination of H2A lysine119(H2AK119ub1) and Monoubiquitination of $\mathrm{H} 2 \mathrm{~B}$ lysine123 in yeast (in human H2BK120ub1) are two well-characterised histone uniquitimation sites. H2AK119ub1 is related to polycomb proteins, which mediate transcription repression. ${ }^{[97]}$ H2BK123ub1 is involved in the promotion of transcriptional elongation and chromatin reassembly. ${ }^{[98]}$

\section{Chromatin structure}

Although the nucleosome, which is a basic unit of chromatin structure, has been well studied, the structure of chromatin itself remains unclear. Chromatin structure is tightly related to biological processes such as transcription, translation, and repair. In most common textbooks, the $30 \mathrm{~nm}$ chromatin fiber is presumed to be the predominant higher-order chromatin structure. However, recent reports using the EM and Cryo-EM techniques have shown structures different from the $30 \mathrm{~nm}$ fiber. ${ }^{[99],[100],[101]}$ Rather than the $30 \mathrm{~nm}$ fiber structure, they propose that the chromatin fiber can assemble into a large chromatin globular structure. ${ }^{[102]}$

\subsection{Chromatin basic unit: tetranucleosome structure}

The tetranucleosome structure is a basic unit of higher-order chromatin structure. The crystal structure of the tetranucleosome was first reported in 2005. ${ }^{[103]}$ The template DNA that was used by these authors contained four 167-bp units consisting of the 147-bp 601 nucleosome position sequence and a 20-bp linker. The structure exhibits a zigzag nucleosome pattern (Figure 11a). The tetranucleosome comprises two stacks of two nucleosome cores and linker DNA connecting them zigzag, back and forth between two stacks of nucleosome cores. In 2014, the cryo-EM structure of the chromatin fiber was reported (Figure 11b). ${ }^{[104]}$ In that report, two types of template DNA were used: (1) 12 units of a 167-bp sequence comprising the 147-bp 601 sequence and a 20-bp linker; and (2) 12 units of a 177-bp sequence comprising the 147-bp 601 sequence and a 30-bp linker. The tetranucleosome structure was formed in both situations and the authors proposed that nucleosome stacking is related to the internucleosomal interaction between the positive $\mathrm{N}$ terminus of histone $\mathrm{H} 4$ and the acidic patch of the $\mathrm{H} 2 \mathrm{~A}-\mathrm{H} 2 \mathrm{~B}$ dimer observed in the nucleosome core-particle structure. (a)

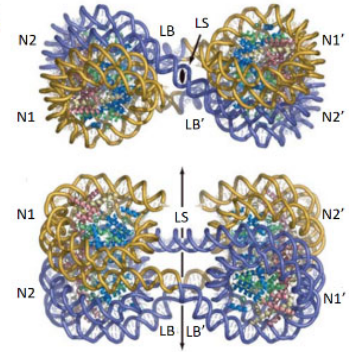

(b)

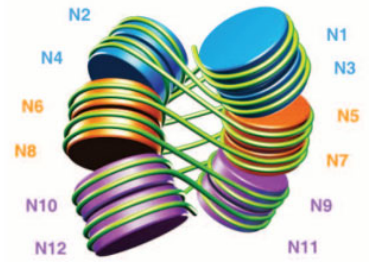

(d)

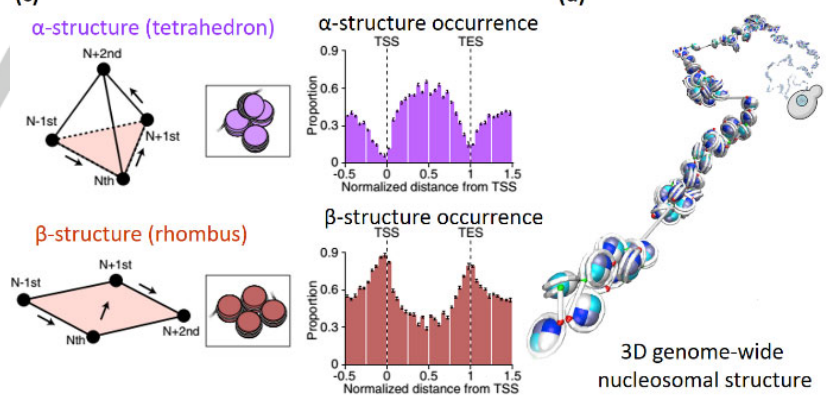

Figure 11. Basic unit of chromatin-tetranucleosome. (a) Crystal structure of tetranucleosome in in vitro reconstituted chromatin. ${ }^{[03]}$ (b) Schematic representation of the cryo-EM structure of $30 \mathrm{~nm}$ chromatin fiber in vitro. ${ }^{[104]}$ (c) Two types of tetranucleosome motifs in yeast genome: the $\alpha$-tetrahedron motif occurs to a greater extent in gene promoters, whereas the $\beta$-rhombus motif occurs more often in the gene body. ${ }^{[105]}$ Normalization was done for each gene locus by dividing by the number of nucleosomes so that TSS and transcription end sites (TESs) are represented by 0 and 1, respectively. (d) 3D genome-wide nucleosomal structure.

In 2019, the tetranucleosome structure was reported in yeast cells using $\mathrm{Hi}-\mathrm{CO}$ method which coupled nucleosome resolution $\mathrm{Hi}-\mathrm{C}$ with nucleosome orientation modified $\mathrm{Hi}-\mathrm{C}$ technology, with 
simulated annealing-molecular dynamics (SA-MD) simulation. ${ }^{[105]}$ In contrast to the normal $\mathrm{Hi}-\mathrm{C}$ method, to reach sub-nucleosomal resolution analysis, the authors used micrococcal nuclease (MNase) to cut the linker DNA between the nucleosomes after fixing the chromosomes, to fragment the chromosomes to the single-nucleosome level. Molecular dynamics (MDs) simulation was used to reconstruct 3D structural modeling of nucleosomes with their orientations(Figure 11d). This study confirmed not only that the tetranucleosome is a basic unit of chromatin but also that the nucleosome folding structure is related to genome functionality. The authors proposed that two types of tetranucleosome motifs, i.e., $\alpha$-tetrahedron and $\beta$ rhombus motifs, exist in nucleosome folding and that the $\alpha$ tetrahedron motif occurs to a greater extent in gene bodies, whereas the $\beta$-rhombus motif occurs to a greater extent in TSS and transcription end site (TES) regions (Figure 11c). The relationship between motifs with specific nucleosome positioning and orientation and epigenetic features at individual loci was uncovered using mutants and cell-cycle-synchronized cells.

\subsection{Nucleosome interaction and chromatin}

\subsubsection{Linker histone $\mathrm{H} 1$ and chromatin}

Linker histones associate with nucleosomes to promote the formation of higher-order chromatin structures. The cryo-EM structure of the linker histone $\mathrm{H} 1$ was described in 2017 using the 197-bp-DNA containing the 147-bp 601 sequence and a 50-bp linker region. ${ }^{[106]}$ By drawing the two linkers together and reducing their flexibility, $\mathrm{H} 1$ shifts the conformational landscape of the nucleosome. The C-terminal domain (CTD) of $\mathrm{H} 1$ localizes primarily to linker DNA, while the $\mathrm{H} 1$ globular domain contacts both linkers and the nucleosome dyad. The binding mode of $\mathrm{H} 1$ is asymmetric and may affect chromatin structure assembly. (a)

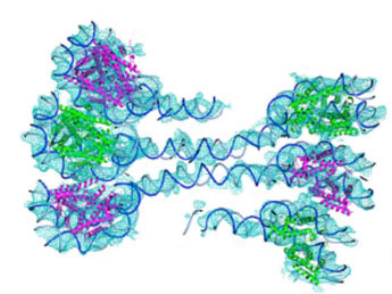

(c)

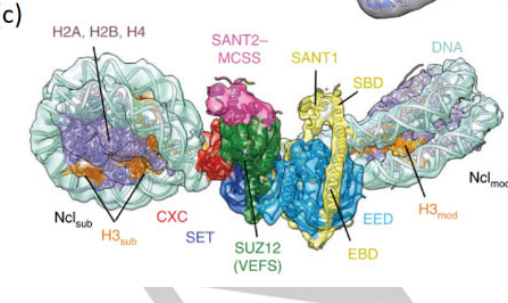

(b)

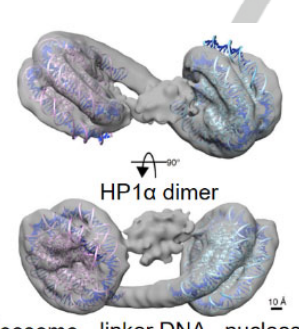

nucleosome linker DNA nucleosome

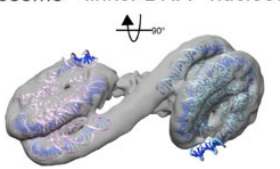

Figure 12. Proteins that affect chromatin fiber structure. (a) Crystal structure of a six-nucleosome array in a stoichiometric complex with full-length $\mathrm{H} 1 .^{[107]}$ (b) Cryo-EM structure of the HP1 protein bound to H3K9 trimethylated dinucleosome. ${ }^{[108]}$ (c) Cryo-EM structure of the PRC2 complex simultaneously engaged by a modified nucleosome and a substrate nucleosome. ${ }^{[109]}$
The crystal structure (9.7 $\AA$ resolution) of a six-nucleosome array bound to linker histone $\mathrm{H} 1$ was reported in 2018. ${ }^{[107]}$ The structure shows a flat two-start ladder-like conformation and a nucleosome packing density that is only half that of a twisted 30 $\mathrm{nm}$ fiber (Figure 12a). The authors also reported that even a minor change in the ionic environment shifts the conformational landscape to a more compact twisted form. This report confirms the role of $\mathrm{H} 1$ in compacting the chromatin fiber.

\subsubsection{HP1 and heterochromatin structure}

Although heterochromatin plays important roles in transcriptional silencing and genome maintenance, the mechanism of heterochromatin formation remains unclear. Heterochromatin protein 1 (HP1) specifically binds to chromatin containing H3K9me3 nucleosome and plays a role in constitutive heterochromatin formation. Full-length HP1 is divided into an Nterminal chromodomain (CD), a C-terminal chromoshadow domain (CSD), and a hinge domain. The CD domain recognizes $\mathrm{H} 3 \mathrm{~K} 9 \mathrm{me}$, while the CSD domain mediates the formation of the HP1 homodimer. ${ }^{[110],[111]}$ The cryo-EM structure of HP1 bound to the H3K9me3 dinucleosome was reported in 2018 (Figure 12b), which showed that HP1 can form a symmetric dimer that bridges two H3K9me3 nucleosomes, whereas the linker DNA region does not interact with HP1. ${ }^{[108]}$ Using the single-molecule Förster resonance energy transfer (FRET) method and a 12-mer chromatin fiber, researchers studied the dynamic progress of HP1 binding to $\mathrm{H} 3 \mathrm{~K} 9 \mathrm{me} 3$ nucleosome and found that it is not as tight as thought previously. It transiently stabilizes stacked nucleosomes, and the compact state remains dynamic. ${ }^{[112]}$

\subsubsection{PRC2 methylates $\mathrm{H} 3$ lysine 27}

Polycomb group proteins maintain the gene-expression pattern of different cells by regulating chromatin structure. PRC2 catalyzes the methylation of histone $\mathrm{H} 3$ at lysine 27 , which leads to facultative heterochromatin formation and contributes to chromatin compaction and transcriptional repression. Recently, the cryo-EM structure of the PRC2 complex and bifunctional dinucleosome was reported (Figure 12c). ${ }^{[109]}$ The PRC2 complex contains four core subunits, i.e., enhancer of zeste homologue 2 (EZH2), embryonic ectoderm development (EED), suppressor of zeste 12 (SUZ12), and RBAP46 or RBAP48. This structure showed that, via interactions with nucleosomal DNA, the PRC2 complex positions the $\mathrm{H} 3$ tails of the activating nucleosome, which interacts with the EED subunit, whereas the substrate nucleosome interacts with the SET domain of EZH2.

6. Atomic force microscopy (AFM) for nucleosome research AFM can be used to observe proteins and protein complexes directly. The sample preparation for AFM imaging is much easier than that required for electron microscopy (EM). In recent years, the AFM fluid mode has been increasingly used in biological research. In contrast with EM and the AFM air mode, the AFM fluid mode allows the observation of protein dynamics in the solution phase. Therefore, the AFM method is widely used to study nucleosome structure and dynamics. Representative examples are provided below. 
(a)

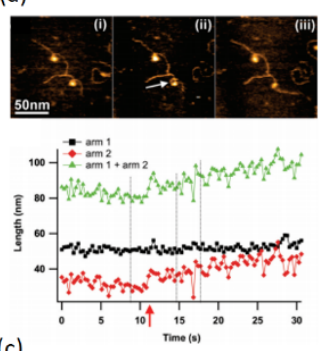

(c)

(b)
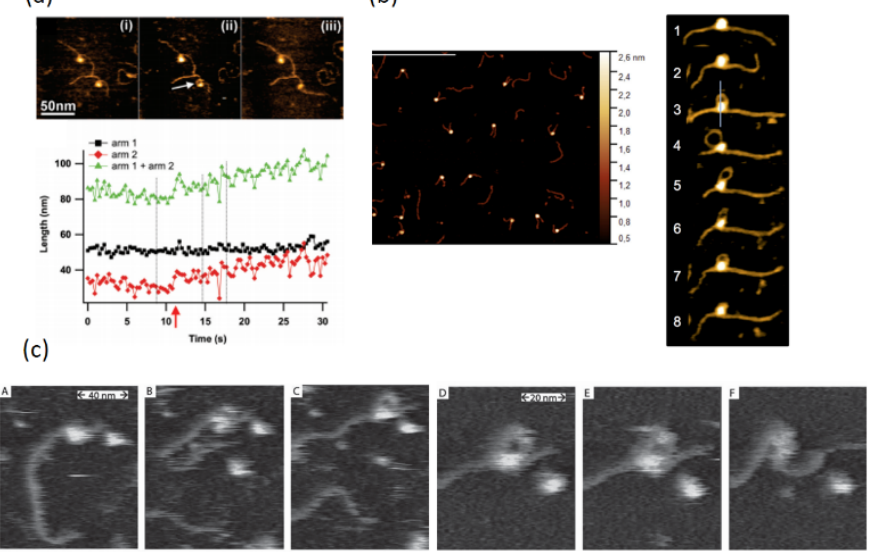

Figure 13. Use of the AFM method to study nucleosomes. (a) Dynamics of nucleosome disassembly, as observed using time-lapse high-speed AFM. ${ }^{[113]}$ (b) CENP-A nucleosome structure (left) and dynamics of loop formation of CENP-A nucleosomes (right). ${ }^{[114]}$ (c) Loop formation during tetrasome disassembly. ${ }^{[115]}$

In 2011, researchers observed a mononucleosome on a 353bp DNA template in a study that looked into dynamic changes in nucleosomes (Figure 13a) ${ }^{[113]}$ in which, the authors captured the dynamic processes of nucleosome unwrapping. Irreversible sliding of the nucleosome in the presence of CHAPS was also observed.

In 2017, researchers studied CENP-A nucleosome dynamics using AFM (Figure 13b). ${ }^{[14]}$ The authors found that the conformation change of CENP-A nucleosomes is spontaneous and reversible. Conformation changes are divided into two main pathways: unwrapping and looping of the DNA or enabling core transfer between neighboring DNA substrates. These results revealed that CENP-A stabilizes the histone core against dissociation to histone subunits upon unwrapping of the DNA, which provides clues for further studies of CENP-A nucleosome function.

Tetrasome dynamics were also observed by AFM in 2014. ${ }^{[115]}$ During the tetrasome disassembly process, a loop structure was observed, as shown in Figure 13c, which remained stable for several minutes. Other properties of tetrasomes were also discovered, such as sliding on DNA and rotation flipping.

\section{Chemical biology studies of nucleosomes}

In recent years, chemical biology played a pivotal role in understanding structural and chemical properties of nucleosome. So here we introduce such reports.

\subsection{Epigenetic modification and nucleosome structure}

Because DNA methylation and demethylation are important processes in epigenetics, the structural changes that occur in nucleosomes upon DNA methylation have been investigated. ${ }^{[116]}$ Using methylcytosine or hydroxymethylcytosine-substituted DNA, changes in nucleosome morphology were observed and analyzed using AFM. The authors found that cytosine methylation induces overwrapping of the DNA (Figure 14) compared with common nucleosomes. However, cytosine hydroxymethylation has a lesser effect on the overwrapping of the DNA. Different modifications cause structural differences in nucleosomes, which indicates that DNA modification may affect nucleosome compaction and relaxation. $B$

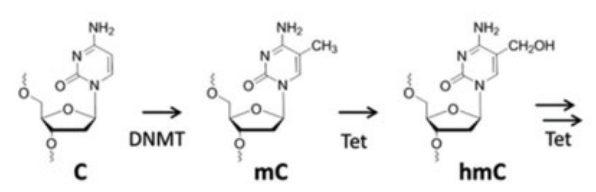

Plasmid containing 601 sequence

$\begin{aligned} \text { PCR dATP, dGTP, dTTP, dC*TP } & =\text { cytosine }(C) \\ & =5 \text {-methylcytosine }(m C)\end{aligned}$

$\begin{aligned} & =5 \text {-methylcytosine }(\mathrm{mC}) \\ & =5 \text {-hydroxymethylcytosine }(\mathrm{hmC})\end{aligned}$

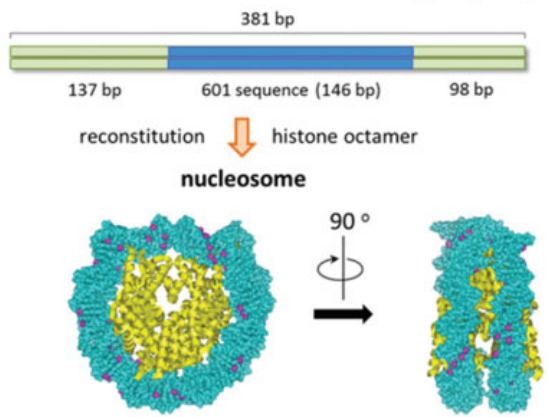

Unmethylated DNA

Methylated DNA
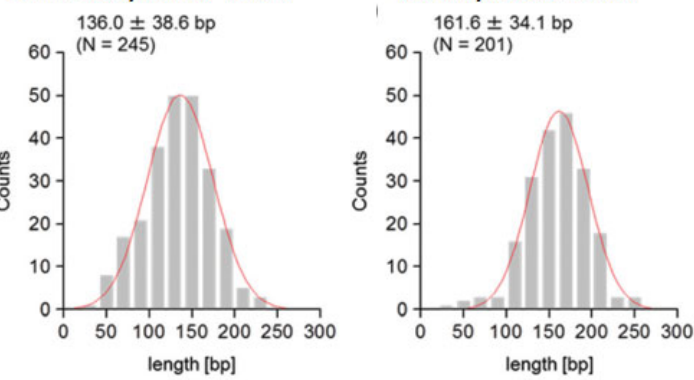

Figure 14. DNA epigenetic modification affects nucleosome wrapping. ${ }^{[116]}$ Upper: Cytosine modification and experimental scheme for the nucleosome reconstitution using a $\mathrm{PCR}$ amplified reconstitution sequence containing modified cytosine. Below: Wrapped length of unmethylated DNA and methylated DNA around the histone octamer.

\subsection{Nucleosome structure alters reaction activity}

To study the reactivity of antitumor agents in a nucleosome architecture, the alkylation level of the antitumor agent duocarmycin B2 on nucleosomes was studied using sequencing gel electrophoresis. ${ }^{[117]}$ Duocarmycin B2 yielded a significant decrease in the efficiency of accessing the nucleosome core DNA, as well as an increase in the efficiency of accessing the linker DNA region in the nucleosome structure (Figure 15a). These results indicate that the efficiency and binding of alkylating agents are decreased in the nucleosome core region, which provides a reference for designing drugs that target key promoter regions. In a subsequent study, capillary electrophoresis was used to investigate the access of $\mathrm{Fe}(\mathrm{II})$ peplomycin and duocarmycin 
B2. ${ }^{[118]}$ MNase was completely prevented from approaching the nucleosome core, whereas the nucleosome core was accessible to duocarmycin B2 and Fe(II) peplomycin with variable levels of suppression. (a)

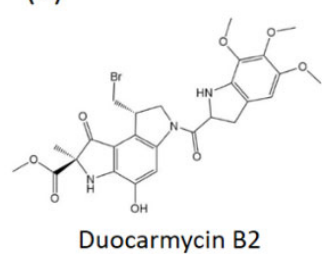

(b)

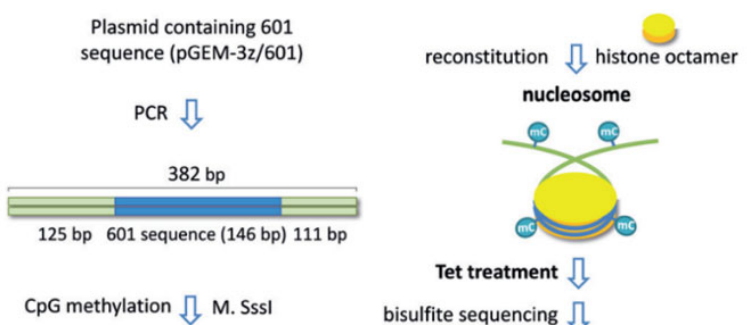

G C G T AC G T G C
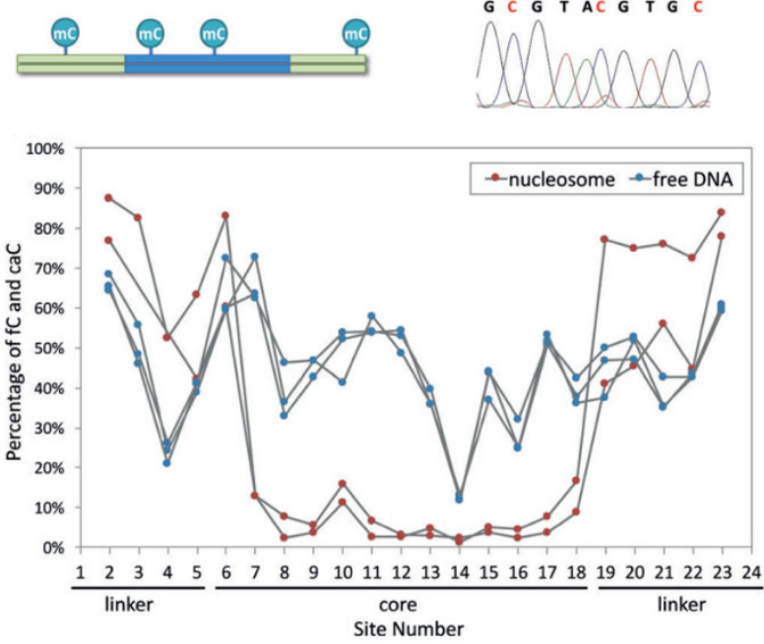

Figure 15. Nucleosome structure alters reaction activity. (a) Structure of duocarmycin B2 and the alkylating efficiencies of duocarmycin B2 are decreased in nucleosome core DNA and increased in the linker DNA region. ${ }^{[117]}$ (b) Upper: Scheme of $\mathrm{CpG}$ methylated nucleosome preparation, followed by Tet treatment and bisulfite sequencing. Below: Oxidation efficiency of Tet1 protein is supressed in nucleosome core region. ${ }^{[119]}$

To investigate the reactivity of Tet proteins in the nucleosome structure, researchers methylated $28 \mathrm{CpG}$ sites on the template DNA using prokaryotic DNA methyltransferase (M.Sssl) and used this kind of DNA to reconstitute nucleosome. The reconstitited nucleosomes were treated with mTet1 and then bisulfite sequencing was performed to identify oxidized methylcytosine sites (Figure 15b). ${ }^{[119]}$ Oxidation efficiency of Tet1 protein was supressed in nucleosome core region which indicates Tet protein prefers to oxidize $\mathrm{mCs}$ located in the linker DNA region of the nucleosome compared with those located in the core DNA region.

\subsection{Using FRET to study nucleosome dynamics}

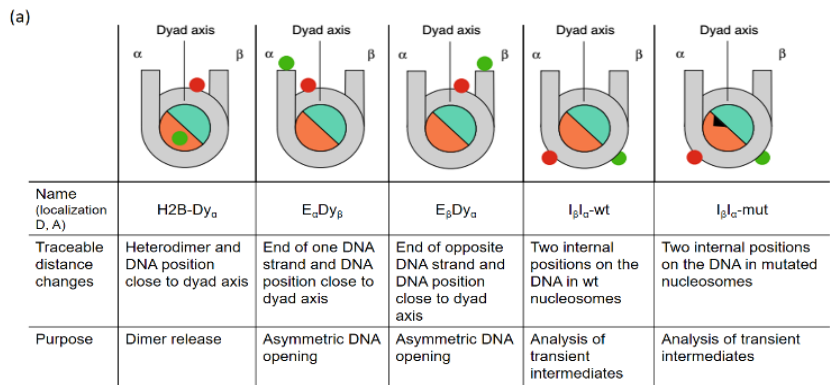

(b)
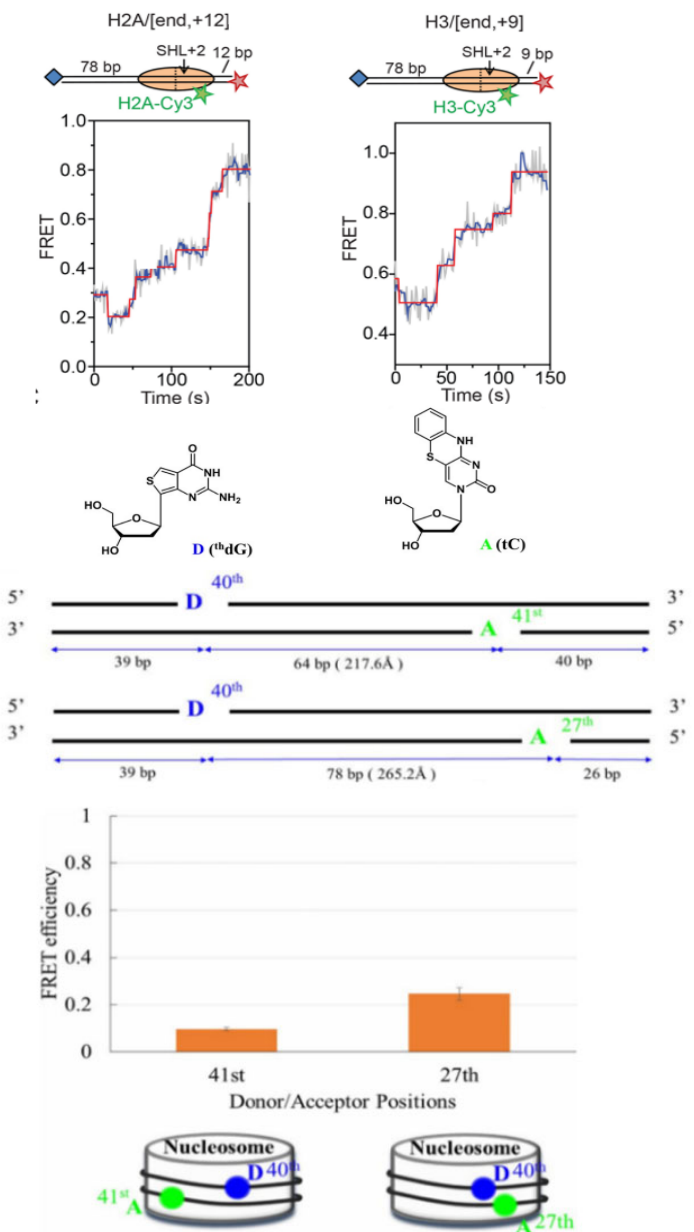

$E_{\text {FRET }}=0.10 \pm 0.01$

Figure 16. Nucleosome conformation change studied by FRET. (a) FRET dye positions in the nucleosome constructs for studying nucleosome conformation change. ${ }^{[120]}$ (b) Stepwise manner in DNA translocation midiated by RSC. ${ }^{[121]}(\mathrm{c})$ Using nucleosomal DNA containing the thdG-tC FRET pair, the FRET efficiency can be changed by placing the donor and acceptor at different positions. ${ }^{[122]}$

Because of the high sensitivity of FRET, it is widely used in nucleosome research. The conformation change of nucleosome was observed using FRET method. ${ }^{[120]} \mathrm{NaCl}$-induced nucleosome destabilization was used here to study nucleosome dynamics. By 
changing the position of FRET pairs as shown in Figure 16a, the opening steps of mononucleosome were observed. Nucleosome disassembly starts with breathing DNA and formation of dynamic octasomes opening in a $50 \mu$ s time frame by an angle of $\approx 20^{\circ}$ each that leads to the weakening or disrupting of one or both the interfaces between the $\mathrm{H} 2 \mathrm{~A}-\mathrm{H} 2 \mathrm{~B}$ dimers and the $\mathrm{H} 3-\mathrm{H} 4$ tetramer. The eviction of one $\mathrm{H} 2 \mathrm{~A}-\mathrm{H} 2 \mathrm{~B}$ dimer leads to a dynamic hexasome with opening dynamics on a $15 \mu$ s time scale and followes by DNA unwrapping and release of second $\mathrm{H} 2 \mathrm{~A}-\mathrm{H} 2 \mathrm{~B}$ dimer.

The process of nucleosome translocation by remodelling factors was studied by FRET system (Figure 16b). ${ }^{[121]}$ Using single-molecule FRET system, authors demonstrated RSC remodels nucleosomes by translocating DNA and that this translocation of DNA is a stepwise process.

By incorporating the highly emissive nucleobase thdG-tC FRET pair ${ }^{[123]}$ into the nucleosome DNA sequence, the FRET efficiencies and orientation factors of the nucleosome change when the location of the donor and acceptor (D40th+A27th and D40th+A41st) on the DNA are modified (Figure 16c). ${ }^{[122]}$ This method provides a useful tool to study nucleosome conformational changes and dynamics. (a)<smiles>CC(=O)NCCCCC(=O)O</smiles>

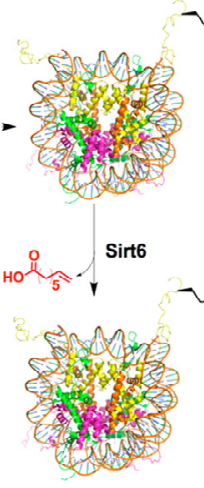

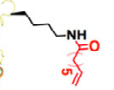<smiles></smiles><smiles>C1CC2CCC(C2)N1</smiles>
sis
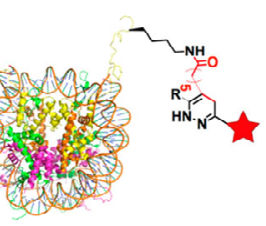

(b)
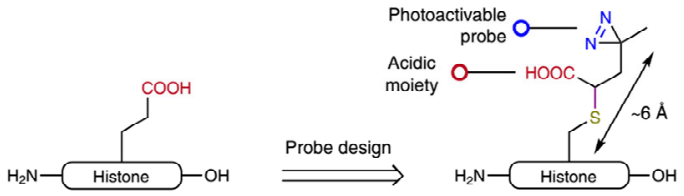

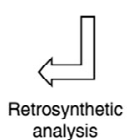
analysis<smiles>CC1(CC(Br)C(=O)O)N=N1</smiles>

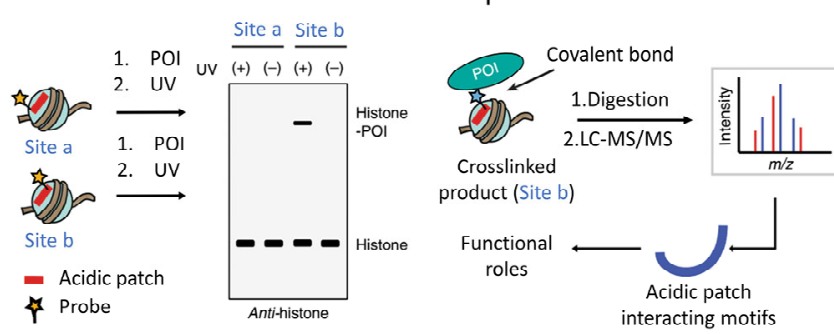

Figure 17. Chemical probes used in nucleosome study. (a) Probing Sirt6targeted lysine deacylation sites in a nucleosome using a chemical biology approach. ${ }^{[124]}$ (b) Incorporation of site-directed photocrosslinking to explore SNF2h engagement with the nucleosome acidic patch. ${ }^{[125]}$

\subsection{Chemical probes used to study nucleosome}

To reveal the target sites of NAD+-dependent histone deacetylases Sirt6, a fatty acylated lysine $\mathrm{N} \varepsilon$-(7-octenoyl)-lysine (OcK) was attached to the potential target position of histone $\mathrm{H} 3$ to create an active Sirt6 substrate. ${ }^{[124]} \mathrm{A}$ tetrazine probe can selectively react with the olefin in the installed fatty acyl-lysine to label the nucleosome. If the fatty acylated site was removed by Sirt6, the probe cannot be added, otherwise the probe can be added (Figure 17a). Using this method, authors found Sirt6 actively removes acylation from $\mathrm{H} 3 \mathrm{~K} 9, \mathrm{H} 3 \mathrm{~K} 18$, and H3K27. Sirt6targeted deacetylation of $\mathrm{H} 3 \mathrm{~K} 18$ and $\mathrm{H} 3 \mathrm{~K} 27$ were confirmed in cells.

To identify the conserved basic motif in the ISWI remodeller SNF2 $h$ that is essential for remodelling, researchers used a photocrosslinking-based nucleosome profiling method, as shown in Figure $17 \mathrm{~b} .{ }^{[125]}$ The photosensitive probe was designed and synthesized on key residues of $\mathrm{H} 2 \mathrm{~A}$ and the $\mathrm{H} 2 \mathrm{~B}$ acidic patch by mutating them to cysteine, followed by alkylation with an electrophilic reagent. After UV irradiation, the acidic patch interaction motif can be crosslinked and can be identified via LC$\mathrm{MS} / \mathrm{MS}$ analysis. A conserved basic motif (acidic patch binding (APB) motif) within SNF2h was identified and biochemical experiments performed using both reconstituted systems and cells indicated that it plays critical roles in chromatin remodelling.

\subsection{NMR and nucleosome study}

To study the crosstalk of histone modifications, a method based on NMR spectroscopy was developed. ${ }^{[126]}$ Since every histone in the nucleosome structure has two copies, authors used two kinds of histones to prepare differentially isotope labelled and asymmetrically modified nucleosomes (Figure 18a). Authors reconstituted asymmetrically modified nucleosomes which contained one modified $\mathrm{H} 3$ and one common $\mathrm{H} 3$. In addition, individual copies of histone $\mathrm{H} 3$ were incorporated in a $15 \mathrm{~N}$ - or 13C-enriched form for selective detection of nucleosome copy by NMR. Gcn5 acetyltransferase mediated H3S10phK14ac crosstalk and asymmetrically decorated nucleosomes with two distinct types of PTM produced by Haspin kinase were observed.

$\mathrm{H} 2 \mathrm{~B}$ ubiquitylation is related to gene activation and disrupts higher-order chromatin compaction; however, the detailed mechanism underlying this process is unclear. Using a chemical biology approach, this mechanism was identified in 2016. ${ }^{[127]}$ In this study, the authors used hydrogen-deuterium (H/D) exchange combined with NMR spectroscopy to detect the distinct residues of ubiquitin that are responsible for its effect on chromatin (Figure 18b). The small acidic patch on ubiquitin comprising Glu16 and Glu18 was selected and its function in chromatin compaction was demonstrated. According to the results of two types of chemical crosslinking experiments and an in vitro chromatin oligomerization assay, the authors showed that ubiquitinubiquitin interactions play an important role in the dissociation of chromatin fibers. 
(a)

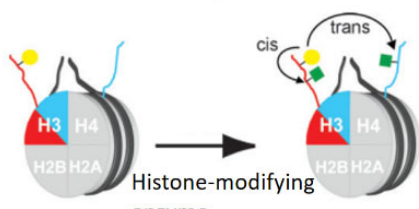

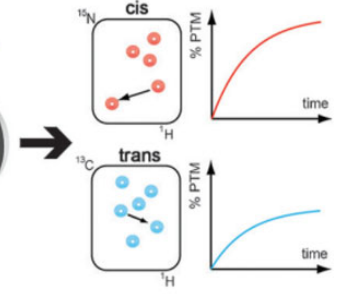

(b) $\begin{aligned} & \text { Prepare } \\ & \text { nucleosome } \\ & \text { arrays }\end{aligned} \rightarrow \begin{aligned} & \text { Exchange protonated } \\ & \text { with deuterated butter, } \\ & \text { incubate with } \mathrm{Mg}^{2+}\end{aligned}$
$\begin{aligned} & \text { incuench exchange, } \\ & \text { reduce disulfide, } \\ & \text { add DMSO }\end{aligned}$$\rightarrow \begin{aligned} & \text { NMR } \\ & { }^{1} \mathrm{H}-{ }^{-15} \mathrm{~N} \mathrm{HSQC}\end{aligned}$

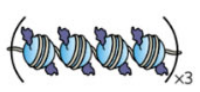

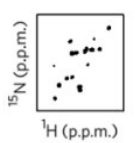

Figure 18. NMR and nucleosome study. (a) Asymmetrically modified and isotopelabeled nucleosomes for NMR-monitoring of asymmetric modification

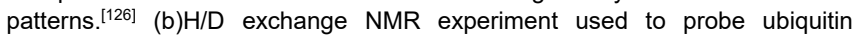
interactions. ${ }^{[127]}$

7.6 Small molecules function in nucleosomal DNA recognition and histone modification based gene activation Pyrrole-imidazole polyamides(PIPs) are sequence-specific DNAbinding ligands which can bind to the minor groove of DNA. Im/Py recognizes GC base pairs and Py/Py recognizes AT or TA base pairs. $\beta$-alanine pair can also recognize AT or TA base pairs. In 2001, to study the DNA accessibility in nucleosome to PIPs, six kinds of hairpin PIPs were designed and tested. ${ }^{[128]}$ The sites on the nucleosomal DNA that were partially or completely facing away from the octamer were found to be fully accessible to PIPs binding. Binding of PIPs to nucleosomal DNA only failed at sites that were completely blocked by interactions with the histone octamer. In the nucleosome structure, the $147 \mathrm{bp}$ DNA wrapped around the octamer structure generates seven minor and six major DNA "supergrooves". A hairpin PIP dimer was designed to bind to the supergrooves for site-specific interaction (Figure 19a). ${ }^{[129]}$ The X-ray crystal structure of the PIP-nucleosome complex showed that the PIP clamp binds to NCP146 across the supergroove as designed, with high specificity. Biochemical studies show that the clamp can increase the stability of the nucleosome against dilution-induced dissociation. Binding of the PIP indicates that the nucleosomal supergroove can be used as a platform for molecular recognition.

Based on the histone modification, small molecules were developed to activate gene expression. Conjugating PIP with an HDAC inhibitor SAHA, SAHA-PIPs were designed for sequenceselective histone acetylation (Figure 19b). ${ }^{[130]}$ SAHA-PIPs activate silenced genes including pluripotency genes, ${ }^{[131][132]}$ germ cellassociated genes, ${ }^{[133]}$ retinal genes, ${ }^{[134]}$ neural genes, ${ }^{[135]}$ and key therapeutically important genes in human dermal fibroblasts. ${ }^{[136]}$ HAT activator N- (4-chloro-3-trifluoromethyl-phenyl)-2-ethoxybenzamide (CTB) was conjugated to PIP for selective HAT regulation of genes. ${ }^{[137]}$ CTB-I(conjugation of CTB and DNA binding domain I) produced similar HAT activity patterns in HeLa cells and HDF cells, indicating it has similar HAT activation properties to SAHA. Bi-PIP was developed for site-specific acetylation by activating histone acetyltransferase
CBP/P300(Figure 19c). ${ }^{[138]}$ Bromodomain inhibitor (Bi) is a small molecule which specifically binds to the pockets of bromodomain to prevent binding with an acetylated lysine residue and used as a mimetic of acetylated lysine recurit P300/CBP. With the selective DNA binder PIP, Bi-PIPs recruit P300 to the nucleosomes having their target DNA sequences and extensively accelerate acetylation in in vitro biochemistry assay. Using Bi-PIP transcriptional activation of genes that have corresponding cognate DNA sequences was also detected in living cells.

(a)

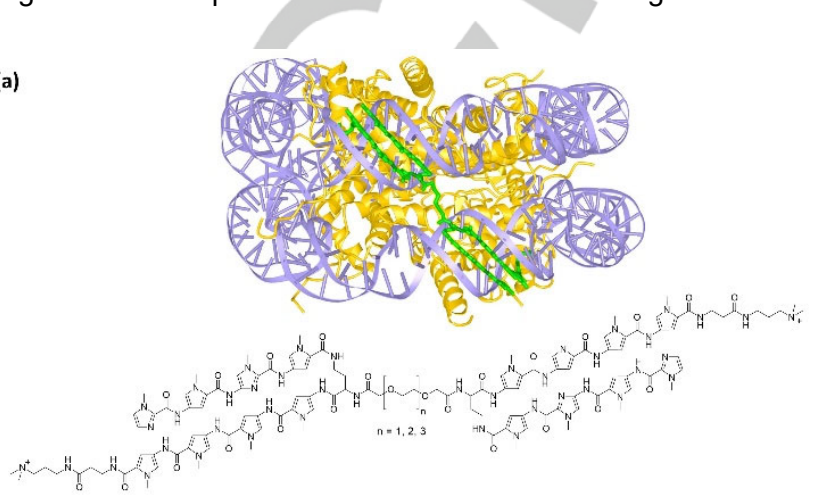

(b)

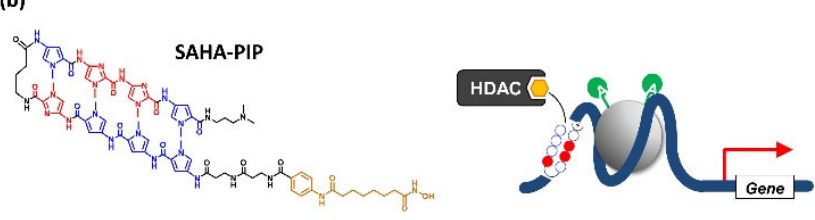

(c)

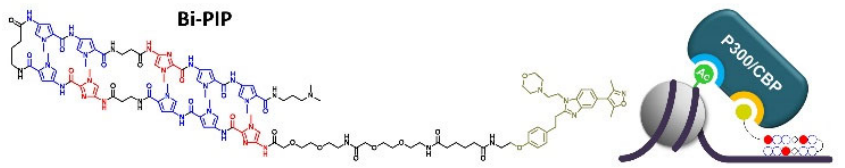

Figure 19 Supergroove binding and gene activation by PIPs (a) Hairpin PIP dimer binds to nucleosome supergroove. ${ }^{[129]}$ (b) Mechanism of SAHA-PIP mediated gene activation. ${ }^{[130]}$ (c) Mechanism of Bi-PIP mediated gene activation. ${ }^{[138]}$

\section{Phase separation and nucleosome}

Phase separation is a commonly observed phenomenon in polymer chemistry ${ }^{[139]}$ and has garnered interest among biologists recently because it plays roles in cellular processes. Many proteins exhibit phase-separation behavior in vitro at high concentrations. ${ }^{[140],[141]}$ Studies have shown that multivalency of the adhesive domain of proteins plays a significant role in driving phase separation. ${ }^{[142]}$ Phase separation is often involved in the assembly of biological molecules in the form of biomolecular condensates, and these types of phase-separated condensates, such as the nucleolus and other membraneless cellular bodies, provide a method to compartmentalize and concentrate biochemical reactions within cells. Here, we discuss the relationship between phase separation and epigenetic events, such as posttranscriptional modification and chromatin structure. 


\subsection{HP1 causes heterochromatin formation and phase} separation

HP1 plays a role in constitutive heterochromatin formation by bridgeing nucleosomes and thus compacting chromatin fibers. A recent study reported that HP1 can form liquid droplets and, via oligomerization to mediate chromatin phase separation, may help compartmentalize the heterochromatin component in cells. ${ }^{[143]}$ The mechanism of HP1-mediated phase separation, which leads to chromatin compaction, was elucidated using Schizosaccharomyces pombe HP1 (Swi6). ${ }^{[144]}$ After binding to HP1, the accessibility and dynamics of buried nucleosome residues was increased in $\mathrm{H} 3 \mathrm{~K} 9 \mathrm{me} 3$ chromatin fibers. This type of nucleosome reshaping increases the opportunity for multivalent interaction between nucleosomes and leads to the compaction of chromatin into liquid droplets (Figure 20). These reports support the phase separation triggered by HP1 and may drive heterochromatin formation and regulate chromatin organization.

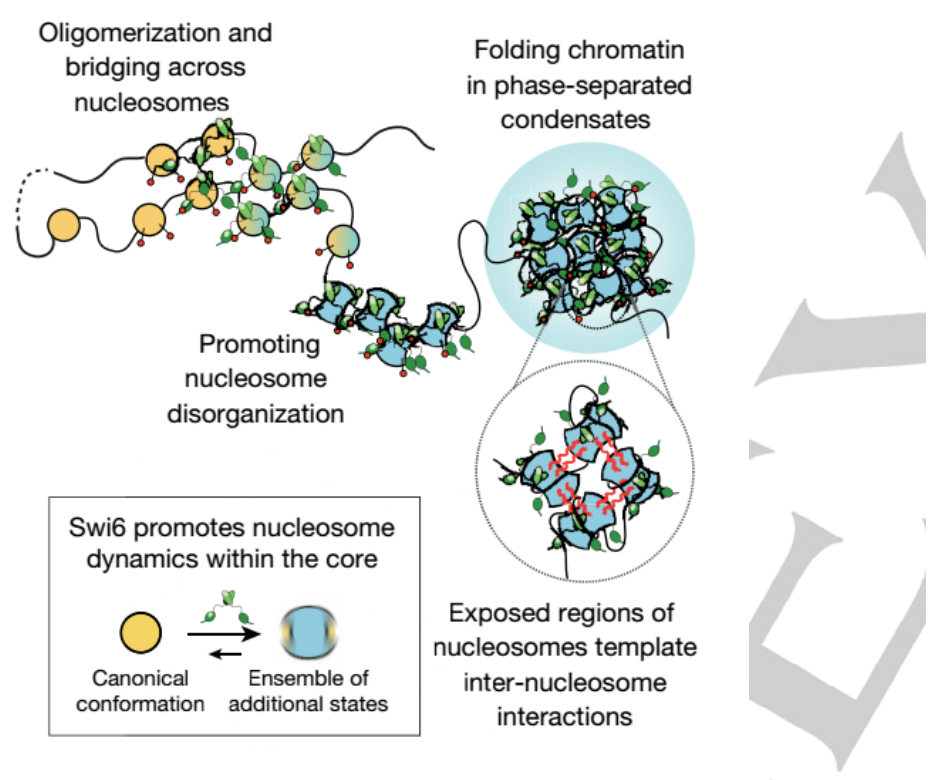

Figure 20. Model for Swi6 (yeast HP1) shapes modified nucleosomes and promotes chromatin phase separation and heterochromatin formation. ${ }^{[144]}$

\subsection{Phase separation promotes nucleosome ubiquitination} As explained above, histone $\mathrm{H} 2 \mathrm{BK} 123$ ubiquitination is related to gene activation. A recent article reported that phase separation accelerates H2BK123 ubiquitination. This report demonstrated that the conserved yeast E3 ubiquitin ligase Bre1 binds to the scaffold protein Lge1, which contains an intrinsically disordered region that causes phase separation. ${ }^{[145]}$ Lge1 condenses into a liquid-like droplet and Bre1 forms a catalytic shell around it. Together, they act as a reaction chamber that recruits the E2 ubiquitin-conjugating enzyme Rad6 and nucleosome substrates and leads to H2B ubiquitination (Figure 21). The authors also proved that the condensate region of Lge1 is required for $\mathrm{H} 2 \mathrm{~B}$ ubiquitination beyond the +1 nucleosome. Although liquid-phase separation is a well-known phenomenon, the relationship between phase separation and gene expression control is not clear. This report suggests that phase separation can regulate enzymatic reactions on chromatin and affect gene regulation.

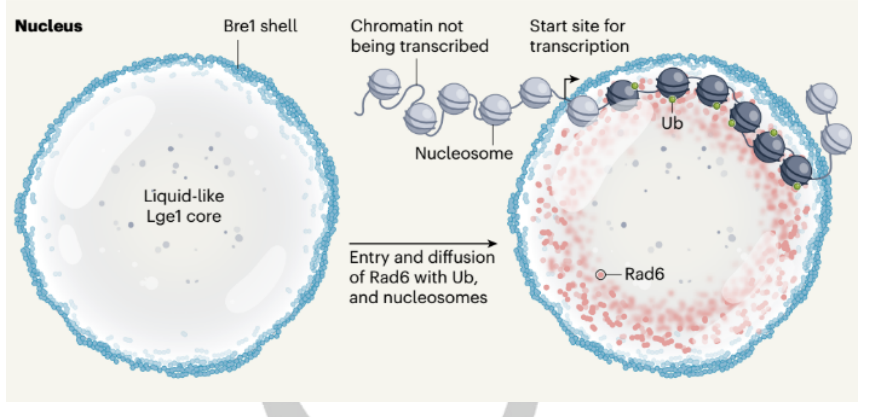

Figure 21. The core-shell structure promotes ubiquitination. ${ }^{[145]}$ (a)

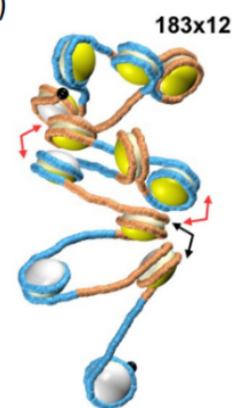

$188 \times 12$ (b)

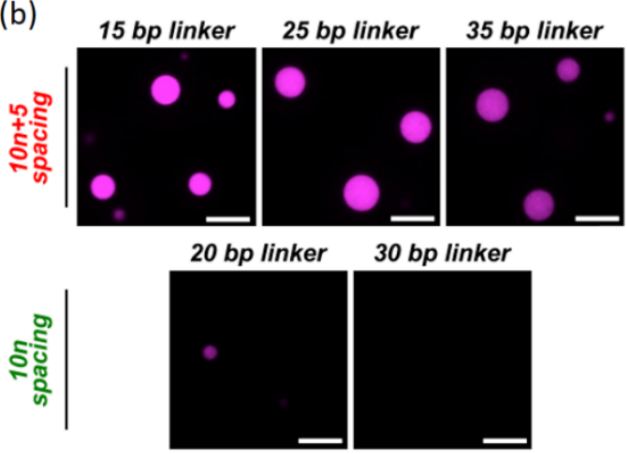

Figure 22. Linker length affects chromatin structure. (a) Nucleosome linkers modulate chromatin folding and topology. ${ }^{[146]}$ Contacts between $n$ and $n+2$ nucleosomes are indicated by black arrows and contacts between $n$ and $n+3$ nucleosomes are indicated by red arrows. (b) Physiological spacing of nucleosomes modulates chromatin droplet density. ${ }^{[147]}$

\subsection{Linker DNA length affects chromatin structure and phase separation}

The length of the linker between two nucleosomes is variable. Moreover, whether it plays a role in the modulation of chromatin structure and function remains unknown. Using EM, DNA topology, native electrophoretic assays, and $\mathrm{Mg}^{2+}$-dependent selfassociation assays, researchers studied the intrinsic folding of linear and circular nucleosome arrays with a linker DNA length of 36-bp and 41-bp. ${ }^{[146]}$ The authors found that the 41-bp linkers promoted interactions between any two nucleosome beads separated by one bead, as expected for a zigzag fiber, whereas 
the 36-bp linkers promoted interactions between two nucleosome beads separated by two other beads, which indicates that different chromatin structures are formed in the presence of linkers with different lengths (Figure 22a). Recently, using liquidliquid phase separation in physiological salt conditions, researchers studied the relationship between linker length and chromatin structure. ${ }^{[147]}$ Surprisingly, they found that the $10 n+5$ spacing favors phase separation, whereas the $10 \mathrm{n}$ spacing disfavors it (Figure 22b). This result indicates that it is easier to form a compact chromatin fiber using the $10 n+5$ spacing fiber, which implies that the length of the linker between two nucleosomes is related to chromatin structure. This report suggests that chromatin itself can lead to phase separation, which may be related to the establishment and maintenance of a distinct chromatin compartment that participates in gene regulation.

\section{Conclusions}

Twenty-three years have elapsed since the structure of the first nucleosome core particle was resolved. Currently, epigenetics has become a hot topic in biology and is increasingly gathering attention among researchers. The nucleosome is no longer simply considered a barrier to transcription, translation or repair because it plays various roles in gene regulation. Using the powerful technique of cryo-EM, a growing number of protein structures and nucleosome complexes have been revealed, which provides additional clues for the investigation of the binding model of the nucleosome and its regulatory factors. Singlemolecule methods such as FRET and AFM are useful for the detailed study of the conformational changes of nucleosomes, which is important for understanding nucleosome dynamics. Different types of chromatin sequencing methods (ChIP-seq, $\mathrm{Hi}$ C, ATAC-seq, etc.) have been developed to investigate the relationship between histone variants, histone modifications, biological functions, chromatin structure, and chromatin accessibility. Super resolution imaging techniques allow singlenucleosome tracking, to study nucleosome dynamics in live cells. ${ }^{[148]}$ The phase separation method offers new ideas to investigate the mechanisms of the binding of protein factors onto chromatin and of chromatin structure formation.

However, many questions regarding nucleosomes remain unanswered. The natural state of chromatin structure remains unclear. Is there any structural difference in the nucleosome folding motif between euchromatin and heterochromatin? The detailed mechanism of protein recruitment onto chromatin and its regulation is undefined. The integration of different methods and the development of new techniques should provide other approaches to study chromatin epigenetics.

\section{Acknowledgements}

This work was supported by a Grant-in-Aid for Scientific Research JSPS KAKENHI (Grant Numbers $16 \mathrm{H} 06356$ and 18KK0139).
Keywords: Histone $\cdot$ nucleosome $\cdot$ chromatin • epigenetic modification $\cdot$ phase separation

[1] R. D. Kornberg, Science 1974, 184, 868-871.

[2] T. J. Richmond, K. Luger, A. W. Mäder, R. K. Richmond, D. F. Sargent, Nature 1997, 389, 251-260.

[3] F. Dong, K. E. Van Holde, Proc. Natl. Acad. Sci. U. S. A. 1991, 88, 10596-10600.

[4] M. Alilat, A. Sivolob, B. Révet, A. Prunell, J. Mol. Biol. 1999, 291, 815-841.

[5] T. Kujirai, H. Ehara, Y. Fujino, M. Shirouzu, S. ichi Sekine, H. Kurumizaka, Science 2018, 362, 595-598.

[6] Y. Li, J. Syed, H. Sugiyama, Cell Chem. Biol. 2016, 23, 1325-1333.

[7] R. Fujita, T. Yamamoto, Y. Arimura, S. Fujiwara, H. Tachiwana, Y. Ichikawa, Y. Sakata, L. Yang, R. Maruyama, M. Hamada, et al., Commun. Biol. 2020, 3, 1-11.

[8] Y. Arimura, H. Tachiwana, T. Oda, M. Sato, H. Kurumizaka, Biochemistry 2012, 51, 3302-3309.

[9] T. Hutcheon, G. H. Dixon, B. Levy-Wilson, J. Biol. Chem. 1980, 255, $681-685$.

[10] L. Locklear, A. J. Ridsdale, D. P. Bazett-Jones, J. R. Davie, Nucleic Acids Res. 1990, 18, 7015-7024.

[11] R. K. McGinty, S. Tan, in Fundam. Chromatin, Springer New York, 2014, pp. 1-28.

[12] D. Kato, A. Osakabe, Y. Arimura, Y. Mizukami, N. Horikoshi, K. Saikusa, S. Akashi, Y. Nishimura, S. Y. Park, J. Nogami, et al., Science 2017, 356, 205-208.

[13] Y. Dalal, H. Wang, S. Lindsay, S. Henikoff, PLoS Biol. 2007, 5, 1798-1809.

[14] T. Furuyama, S. Henikoff, Cell 2009, 138, 104-113.

[15] S. Henikoff, S. Ramachandran, K. Krassovsky, T. D. Bryson, C. A. Codomo, K. Brogaard, J. Widom, J. P. Wang, J. G. Henikoff, Elife 2014, 2014, e01861.

[16] E. M. Dunleavy, W. Zhang, G. H. Karpen, Nat. Struct. Mol. Biol. 2013, 20, 648-650

[17] M. Engeholm, M. De Jager, A. Flaus, R. Brenk, J. Van Noort, T. Owen-Hughes, Nat. Struct. Mol. Biol. 2009, 16, 151-158.

[18] T. Zou, F. Hashiya, Y. Wei, Z. Yu, G. N. Pandian, H. Sugiyama, Chem. - A Eur. J. 2018, 24, 15998-16002.

[19] S. Henikoff, M. M. Smith, Cold Spring Harb. Perspect. Biol. 2015, 7, 1-25.

[20] H. Tachiwana, W. Kagawa, T. Shiga, A. Osakabe, Y. Miya, K. Saito, Y. Hayashi-Takanaka, T. Oda, M. Sato, S.-Y. Park, et al., Nature 2011, 476, 232-235.

[21] H. Kato, J. Jiang, B. R. Zhou, M. Rozendaal, H. Feng, R. Ghirlando, T. S. Xiao, A. F. Straight, Y. Bai, Science 2013, 340, 1110-1113.

[22] S. J. Falk, L. Y. Guo, N. Sekulic, E. M. Smoak, T. Mani, G. A. Logsdon, K. Gupta, L. E. T. Jansen, G. D. Van Duyne, S. A. Vinogradov, et al., Science 2015, 348, 699-703.

[23] Y. Mito, J. G. Henikoff, S. Henikoff, Science 2007, 315, 1408-1411.

[24] C. Wirbelauer, O. Bell, D. Schübeler, Genes Dev. 2005, 19, 17611766.

[25] K. Ahmad, S. Henikoff, Mol. Cell 2002, 9, 1191-1200.

[26] C. Jin, G. Felsenfeld, Genes Dev. 2007, 21, 1519-1529. 
M. Altaf, A. Auger, M. Covic, J. Côté, Biochem. Cell Biol. 2009, 87, 35-50.

[28] J. Zlatanova, A. Thakar, Structure 2008, 16, 166-179.

[29] N. L. Adkins, H. Niu, P. Sung, C. L. Peterson, Nat. Struct. Mol. Biol. 2013, 20, 836-842.

[30] M. Dalvai, L. Fleury, L. Bellucci, S. Kocanova, K. Bystricky, PLoS Genet. 2013, 9, e1003387.

[31] R. Amat, L. J. Gudas, J. Cell. Physiol. 2011, 226, 293-298.

[32] S. Chauhan, D. D. Boyd, Nucleic Acids Res. 2012, 40, 600-613.

[33] R. K. Suto, M. J. Clarkson, D. J. Tremethick, K. Luger, Nat. Struct. Biol. 2000, 7, 1121-1124.

[34] A. J. Morrison, X. Shen, Cell Cycle 2005, 4, 513-512.

[35] B. P. Chadwick, H. F. Willard, Proc. Natl. Acad. Sci. U. S. A. 2004, 101, 17450-17455.

[36] M. D. Lavigne, G. Vatsellas, A. Polyzos, E. Mantouvalou, G. Sianidis, I. Maraziotis, M. Agelopoulos, D. Thanos, Cell Rep. 2015 11, 1090-1101.

[37] P. B. Talbert, S. Henikoff, Nat. Rev. Mol. Cell Biol. 2010, 11, 264275.

[38] D. R. Foltz, L. E. T. Jansen, A. O. Bailey, J. R. Yates, E. A. Bassett, S. Wood, B. E. Black, D. W. Cleveland, Cell 2009, 137, 472-484.

[39] E. M. Dunleavy, D. Roche, H. Tagami, N. Lacoste, D. Ray-Gallet, Y. Nakamura, Y. Daigo, Y. Nakatani, G. Almouzni-Pettinotti, Cell 2009, 137, 485-497.

[40] C. Jin, G. Felsenfeld, Genes Dev. 2007, 21, 1519-1529.

[41] M. J. Kruhlak, A. Celeste, A. Nussenzweig, Methods Mol. Biol, 2009, 523, 125-140.

[42] A. L. Hughes, O. J. Rando, Annu. Rev. Biophys. 2014, 43, 41-63.

[43] A. Martínez-Balbás, A. Rodríguez-Campos, M. García-Ramírez, J. Sainz, P. Carrera, J. Aymamí, F. Azorín, Biochemistry 1990, 29, 2342-2348.

[44] N. Gilbert, J. Allan, Proc. Natl. Acad. Sci. U. S. A. 2001, 98, 1194911954.

[45] P. T. Lowary, J. Widom, J. Mol. Biol. 1998, 276, $19-42$.

[46] L. Xi, Y. Fondufe-Mittendorf, L. Xia, J. Flatow, J. Widom, J. P. Wang, BMC Bioinformatics 2010, 11, 346.

[47] S. Smith, B. Stillman, EMBO J. 1991, 10, 971-980.

[48] B. K. Dennehey, J. Tyler, in Fundam. Chromatin, Springer New York, 2014, pp. 29-67.

[49] T. Munakata, N. Adachi, N. Yokoyama, T. Kuzuhara, M. Horikoshi, Genes to Cells 2000, 5, 221-233.

[50] S. Smith, B. Stillman, Cell 1989, 58, 15-25.

[51] F. Mattiroli, Y. Gu, T. Yadav, J. L. Balsbaugh, M. R. Harris, E. S. Findlay, Y. Liu, C. A. Radebaugh, L. A. Stargell, N. G. Ahn, et al., Elife 2017, 6, e22799.

[52] D. Ray-Gallet, A. Woolfe, I. Vassias, C. Pellentz, N. Lacoste, A. Puri, D. C. Schultz, N. A. Pchelintsev, P. D. Adams, L. E. T. Jansen, et al., Mol. Cell 2011, 44, 928-941.

[53] H. P. J. Voon, L. H. Wong, Nucleic Acids Res. 2016, 44, 14961501.

[54] N. A. Pchelintsev, T. McBryan, T. S. Rai, J. VanTuyn, D. Ray-Gallet, G. Almouzni, P. D. Adams, Cell Rep. 2013, 3, 1012-1019.
H. P. J. Voon, J. R. Hughes, C. Rode, I. A. DeLaRosa-Velázquez, T. Jenuwein, R. Feil, D. R. Higgs, R. J. Gibbons, Cell Rep. 2015, 11, 405-418.

[56] A. D. Goldberg, L. A. Banaszynski, K. M. Noh, P. W. Lewis, S. J. Elsaesser, S. Stadler, S. Dewell, M. Law, X. Guo, X. Li, et al., Cell 2010, 140, 678-691.

[57] Y. Li, J. Syed, Y. Suzuki, S. Asamitsu, N. Shioda, T. Wada, H. Sugiyama, ChemBioChem 2016, 17, 928-935.

[58] N. Shioda, Y. Yabuki, K. Yamaguchi, M. Onozato, Y. Li, K. Kurosawa, H. Tanabe, N. Okamoto, T. Era, H. Sugiyama, et al., Nat. Med. 2018, 24, 802-813.

[59] A. J. Andrews, X. Chen, A. Zevin, L. A. Stargell, K. Luger, Mol. Cell 2010, 37, 834-842.

[60] R. Belotserkovskaya, S. Oh, V. A. Bondarenko, G. Orphanides, V. M. Studitsky, D. Reinberg, Science 2003, 301, 1090-1093.

[61] M. Zhang, H. Liu, Y. Gao, Z. Zhu, Z. Chen, P. Zheng, L. Xue, J. Li, M. Teng, L. Niu, Structure 2016, 24, 1810-1820.

[62] C. Aguilar-Gurrieri, A. Larabi, V. Vinayachandran, N. A. Patel, K. Yen, R. Reja, I.-O. Ebong, G. Schoehn, C. V Robinson, F. Pugh, et al., EMBO J. 2016, 35, 1465-1482.

[63] B. Bartholomew, Annu. Rev. Biochem. 2014, 83, 671-696.

[64] G. J. Narlikar, R. Sundaramoorthy, T. Owen-Hughes, Cell 2013, 154, 490-503.

[65] S. E. Torigoe, D. L. Urwin, H. Ishii, D. E. Smith, J. T. Kadonaga, Mol. Cell 2011, 43, 638-648.

[66] J. Fei, S. E. Torigoe, C. R. Brown, M. T. Khuong, G. A. Kassavetis, H. Boeger, J. T. Kadonaga, Genes Dev. 2015, 29, 2563-2575.

[67] D. F. V. Corona, G. Längst, C. R. Clapier, E. J. Bonte, S. Ferrari, J. W. Tamkun, P. B. Becker, Mol. Cell 1999, 3, 239-245.

[68] P. D. Varga-Weisz, M. Wilm, E. Bonte, K. Dumas, M. Mann, P. B. Becker, Nature 1997, 388, 598-602.

[69] A. Lusser, D. L. Urwin, J. T. Kadonaga, Nat. Struct. Mol. Biol. 2005, $12,160-166$.

[70] H. Boeger, J. Griesenbeck, J. S. Strattan, R. D. Kornberg, Mol. Cell 2004, 14, 667-673.

[71] G. Mizuguchi, X. Shen, J. Landry, W. H. Wu, S. Sen, C. Wu, Science 2004, 303, 343-348.

[72] D. D. Ruhl, J. Jin, Y. Cai, S. Swanson, L. Florens, M. P. Washburn, R. C. Conaway, J. W. Conaway, J. C. Chrivia, Biochemistry 2006, 45, 5671-5677.

[73] Y. Han, A. A. Reyes, S. Malik, Y. He, Nature 2020, 579, 452-455.

[74] F. R. Wagner, C. Dienemann, H. Wang, A. Stützer, D. Tegunov, H. Urlaub, P. Cramer, Nature 2020, 579, 448-451.

[75] S. Eustermann, K. Schall, Di. Kostrewa, K. Lakomek, M. Strauss, M. Moldt, K. P. Hopfner, Nature 2018, 556, 386-390.

[76] L. Farnung, S. M. Vos, C. Wigge, P. Cramer, Nature 2017, 550, 539-542.

[77] C. R. Clapier, J. Iwasa, B. R. Cairns, C. L. Peterson, Nat. Rev. Mol. Cell Biol. 2017, 18, 407-422.

[78] R. Holliday, J. Pugh, Science 1975, 187, 226-232.

[79] S. F. Wolf, D. J. Jolly, K. D. Lunnen, T. Friedmann, B. R. Migeon, Proc. Natl. Acad. Sci. U. S. A. 1984, 81, 2806-2810.

[80] M. F. Robert, S. Morin, N. Beaulieu, F. Gauthier, I. C. Chute, A. Barsalou, A. R. MacLeod, Nat. Genet. 2003, 33, 61-65. 
M. Tahiliani, K. P. Koh, Y. Shen, W. A. Pastor, H. Bandukwala, Y.

Brudno, S. Agarwal, L. M. Iyer, D. R. Liu, L. Aravind, et al., Science 2009, 324, 930-935.

[82] Y. F. He, B. Z. Li, Z. Li, P. Liu, Y. Wang, Q. Tang, J. Ding, Y. Jia, Z. Chen, N. Li, et al., Science 2011, 333, 1303-1307.

[83] S. Ito, L. Shen, Q. Dai, S. C. Wu, L. B. Collins, J. A. Swenberg, C. He, Y. Zhang, Science 2011, 333, 1300-1303.

[84] X. Xing, S. Sato, N.-K. Wong, K. Hidaka, H. Sugiyama, M. Endo, Nucleic Acids Res. 2020, 48, 4041-4051.

[85] A. Schön, E. Kaminska, F. Schelter, E. Ponkkonen, E. Korytiaková, S. Schiffers, T. Carell, Angew. Chemie Int. Ed. 2020, 59, 55915594.

[86] K. Yamatsugu, S. A. Kawashima, M. Kanai, Curr. Opin. Chem. Biol. 2018, 46, 10-17.

[87] W. Fischle, H. D. Mootz, D. Schwarzer, Curr. Opin. Chem. Biol. 2015, 28, 131-140.

[88] D. M. PHILLIPS, Biochem. J. 1963, 87, 258-263.

[89] W. Zhang, EMBO J. 1998, 17, 3155-3167.

[90] G. E. Zentner, S. Henikoff, Nat. Struct. Mol. Biol. 2013, 20, 259266.

[91] A. M. Martin, D. J. Pouchnik, J. L. Walker, J. J. Wyrick, Genetics 2004, 167, 1123-1132.

[92] M. F. Dion, S. J. Altschuler, L. F. Wu, O. J. Rando, Proc. Natl. Acad. Sci. U. S. A. 2005, 102, 5501-5506.

[93] Z. W. Sun, C. D. Allis, Nature 2002, 418, 104-108.

[94] B. Fierz, C. Chatterjee, R. K. McGinty, M. Bar-Dagan, D. P. Raleigh, T. W. Muir, Nat. Chem. Biol. 2011, 7, 113-119.

[95] J. Kim, M. Guermah, R. K. McGinty, J. S. Lee, Z. Tang, T. A. Milne, A. Shilatifard, T. W. Muir, R. G. Roeder, Cell 2009, 137, 459-471.

[96] H. Xue, T. Yao, M. Cao, G. Zhu, Y. Li, G. Yuan, Y. Chen, M. Lei, J. Huang, Nature 2019, 573, 445-449.

[97] H. Wang, L. Wang, H. Erdjument-Bromage, M. Vidal, P. Tempst, R. S. Jones, Y. Zhang, Nature 2004, 431, 873-878.

[98] G. Fuchs, M. Oren, Biochim. Biophys. Acta - Gene Regul. Mech 2014, 1839, 694-701.

[99] E. Fussner, R. W. Ching, D. P. Bazett-Jones, Trends Biochem. Sci. 2011, 36, 1-6.

[100] M. Eltsov, K. M. MacLellan, K. Maeshima, A. S. Frangakis, J. Dubochet, Proc. Natl. Acad. Sci. U. S. A. 2008, 105, 19732-19737.

[101] K. Maeshima, M. Eltsov, J. Biochem. 2008, 143, 145-153.

[102] K. Maeshima, R. Rogge, S. Tamura, Y. Joti, T. Hikima, H. Szerlong, C. Krause, J. Herman, E. Seidel, J. DeLuca, et al., EMBO J. 2016, 35, 1115-1132.

[103] T. Schalch, S. Duda, D. F. Sargent, T. J. Richmond, Nature 2005 436, 138-141.

[104] F. Song, P. Chen, D. Sun, M. Wang, L. Dong, D. Liang, R. M. Xu, P Zhu, G. Li, Science 2014, 344, 376-380.

[105] M. Ohno, T. Ando, D. G. Priest, V. Kumar, Y. Yoshida, Y. Taniguchi, Cell 2019, 176, 520-534.

[106] J. Bednar, I. Garcia-Saez, R. Boopathi, A. R. Cutter, G. Papai, A. Reymer, S. H. Syed, I. N. Lone, O. Tonchev, C. Crucifix, et al., Mol. Cell 2017, 66, 384-397.e8.
[107] I. Garcia-Saez, H. Menoni, R. Boopathi, M. S. Shukla, L. Soueidan, M. Noirclerc-Savoye, A. Le Roy, D. A. Skoufias, J. Bednar, A. Hamiche, et al., Mol. Cell 2018, 72, 902-915.e7.

[108] S. Machida, Y. Takizawa, M. Ishimaru, Y. Sugita, S. Sekine, J. ichi Nakayama, M. Wolf, H. Kurumizaka, Mol. Cell 2018, 69, 385-397.

[109] S. Poepsel, V. Kasinath, E. Nogales, Nat. Struct. Mol. Biol. 2018, 25, 154-162.

[110] D. Canzio, A. Larson, G. J. Narlikar, Trends Cell Biol. 2014, 24 377-386.

[111] G. Nishibuchi, S. Machida, A. Osakabe, H. Murakoshi, K. HiragamiHamada, R. Nakagawa, W. Fischle, Y. Nishimura, H. Kurumizaka, H. Tagami, et al., Nucleic Acids Res. 2014, 42, 12498-12511.

[112] S. Kilic, S. Felekyan, O. Doroshenko, I. Boichenko, M. Dimura, H. Vardanyan, L. C. Bryan, G. Arya, C. A. M. Seidel, B. Fierz, Nat. Commun. 2018, 9, 1-14.

[113] A. Miyagi, T. Ando, Y. L. Lyubchenko, Biochemistry 2011, 50, 79017908.

[114] M. P. Stumme-Diers, S. Banerjee, M. Hashemi, Z. Sun, Y. L. Lyubchenko, Nucleic Acids Res. 2018, 46, 94-103.

[115] A. J. Katan, R. Vlijm, A. Lusser, C. Dekker, Small 2015, 11, 976984.

[116] S. Kizaki, Y. Suzuki, T. Takenaka, M. Endo, H. Sugiyama, Biomater Sci. 2014, 2, 1399.

[117] T. Zou, S. Kizaki, G. N. Pandian, H. Sugiyama, Chem. - A Eur. J. 2016, 22, 8756-8758.

[118] T. Zou, S. Kizaki, H. Sugiyama, ChemBioChem 2018, 19, 664-668.

[119] S. Kizaki, T. Zou, Y. Li, Y. W. Han, Y. Suzuki, Y. Harada, H. Sugiyama, Chem. - A Eur. J. 2016, 22, 16598-16601.

[120] A. Gansen, S. Felekyan, R. Kühnemuth, K. Lehmann, K. Tóth, C. A. M. Seidel, J. Langowski, Nat. Commun. 2018, 9, 1-13.

[121] B. T. Harada, W. L. Hwang, S. Deindl, N. Chatterjee, B. Bartholomew, X. Zhuang, Elife 2016, 5, e10051.

[122] J. H. Han, S. Park, F. Hashiya, H. Sugiyama, Chem. - A Eur. J. 2018, 24, 17091-17095.

[123] J. H. Han, S. Yamamoto, S. Park, H. Sugiyama, Chem. - A Eur. J. 2017, 23, 7607-7613.

[124] W. W. Wang, Y. Zeng, B. Wu, A. Deiters, W. R. Liu, ACS Chem. Biol. 2016, 11, 1973-1981.

[125] H. T. Dao, B. E. Dul, G. P. Dann, G. P. Liszczak, T. W. Muir, Nat. Chem. Biol. 2020, 16, 134-142.

[126] S. Liokatis, R. Klingberg, S. Tan, D. Schwarzer, Angew. Chemie 2016, 128, 8402-8405.

[127] G. T. Debelouchina, K. Gerecht, T. W. Muir, Nat. Chem. Biol. 2017, 13, 105-110.

[128] J. M. Gottesfeld, C. Melander, R. K. Suto, H. Raviol, K. Luger, P. B. Dervan, J. Mol. Biol. 2001, 309, 615-629.

[129] R. S. Edayathumangalam, P. Weyermannt, J. M. Gottesfeld, P. B. Dervants, K. Luger, Proc. Natl. Acad. Sci. U. S. A. 2004, 101, 68646869.

[130] A. Ohtsuki, M. T. Kimura, M. Minoshima, T. Suzuki, M. Ikeda, T. Bando, H. Nagase, K. ichi Shinohara, H. Sugiyama, Tetrahedron Lett. 2009, 50, 7288-7292.

[131] G. N. Pandian, Y. Nakano, S. Sato, H. Morinaga, T. Bando, H. Nagase, H. Sugiyama, Sci. Rep. 2012, 2, 1-8. 
[132] G. N. Pandian, S. Sato, C. Anandhakumar, J. Taniguchi, K. Takashima, J. Syed, L. Han, A. Saha, T. Bando, H. Nagase, et al., ACS Chem. Biol. 2014, 9, 2729-2736.

[133] L. Han, G. N. Pandian, S. Junetha, S. Sato, C. Anandhakumar, J. Taniguchi, A. Saha, T. Bando, H. Nagase, H. Sugiyama, Angew. Chemie 2013, 125, 13652-13655.

[134] J. Syed, A. Chandran, G. N. Pandian, J. Taniguchi, S. Sato, K. Hashiya, G. Kashiwazaki, T. Bando, H. Sugiyama, ChemBioChem 2015, 16, 1497-1501.

[135] Y. Wei, G. N. Pandian, T. Zou, J. Taniguchi, S. Sato, G. Kashiwazaki, T. Vaijayanthi, T. Hidaka, T. Bando, H. Sugiyama, ChemistryOpen 2016, 5, 517-521.

[136] G. N. Pandian, J. Taniguchi, S. Junetha, S. Sato, L. Han, A. Saha, C. Anandhakumar, T. Bando, H. Nagase, T. Vaijayanthi, et al., Sci. Rep. 2014, 4, 1-8.

[137] L. Han, G. N. Pandian, A. Chandran, S. Sato, J. Taniguchi, G. Kashiwazaki, Y. Sawatani, K. Hashiya, T. Bando, Y. Xu, et al., Angew. Chemie 2015, 127, 8824-8827.

[138] J. Taniguchi, Y. Feng, G. N. Pandian, F. Hashiya, T. Hidaka, K. Hashiya, S. Park, T. Bando, S. Ito, H. Sugiyama, J. Am. Chem. Soc. 2018, 140, 7108-7115.

[139] P. J. Flory, J. Chem. Phys. 1942, 10, 51-61.

[140] J. A. Riback, C. D. Katanski, J. L. Kear-Scott, E. V. Pilipenko, A. E. Rojek, T. R. Sosnick, D. A. Drummond, Cell 2017, 168, 10281040.e19.
[141] B. R. Sabari, A. Dall'Agnese, A. Boija, I. A. Klein, E. L. Coffey, K. Shrinivas, B. J. Abraham, N. M. Hannett, A. V. Zamudio, J. C. Manteiga, et al., Science 2018, 361, eaar3958.

[142] S. Boeynaems, S. Alberti, N. L. Fawzi, T. Mittag, M. Polymenidou, F. Rousseau, J. Schymkowitz, J. Shorter, B. Wolozin, L. Van Den Bosch, et al., Trends Cell Biol. 2018, 28, 420-435.

[143] A. G. Larson, D. Elnatan, M. M. Keenen, M. J. Trnka, J. B. Johnston, A. L. Burlingame, D. A. Agard, S. Redding, G. J. Narlikar, Nature 2017, 547, 236-240.

[144] S. Sanulli, M. J. Trnka, V. Dharmarajan, R. W. Tibble, B. D. Pascal, A. L. Burlingame, P. R. Griffin, J. D. Gross, G. J. Narlikar, Nature 2019, 575, 390-394.

[145] L. D. Gallego, M. Schneider, C. Mittal, A. Romanauska, R. M. Gudino Carrillo, T. Schubert, B. F. Pugh, A. Köhler, Nature 2020, 579, 592-597.

[146] M. V. Bass, T. Nikitina, D. Norouzi, V. B. Zhurkin, S. A. Grigoryev, J. Biol. Chem. 2019, 294, 4233-4246.

[147] B. A. Gibson, L. K. Doolittle, M. W. G. Schneider, L. E. Jensen, N. Gamarra, L. Henry, D. W. Gerlich, S. Redding, M. K. Rosen, Cell 2019, 179, 470-484.

[148] T. Nozaki, R. Imai, M. Tanbo, R. Nagashima, S. Tamura, T. Tani, Y Joti, M. Tomita, K. Hibino, M. T. Kanemaki, et al., Mol. Cell 2017, 67, 282-293.

[149] B. R. Keppler, T. K. Archer, Expert Opin. Ther. Targets 2008, 12, 1301-1312. 
WILEY-VCH

\section{Entry for the Table of Contents}

\section{FULL PAPER}

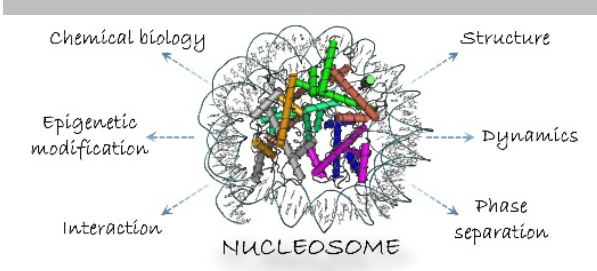
We review recent progress in the researches on nucleosomes and epigenetics, from nucleosome structure to chromatin formation with a focus on chemical aspects. Basic knowledge of nucleosome (nucleosome structure, nucleosome position sequence, nucleosome assembly and remodelling), epigenetic modifications, chromatin structure, chemical biology methods and nucleosome, observation nucleosome by AFM, phase separation and nucleosome are described.

Yihong Feng, Masayuki Endo, * and Hiroshi Sugiyama*

Page No. - Page No.

Nucleosomes and epigenetics from a chemical perspective 